\title{
RMetS
}

\section{The mesoscale structure of a polar low: airborne lidar measurements and simulations}

\author{
J. S. Wagner, ${ }^{\text {a` }}$ A. Gohm, ${ }^{\text {a }}$ A. Dörnbrack ${ }^{\mathrm{b}}$ and A. Schäfler ${ }^{\mathrm{b}}$ \\ ${ }^{a}$ Institute of Meteorology and Geophysics, University of Innsbruck, Innsbruck, Austria \\ ${ }^{\mathrm{b}}$ Institut für Physik der Atmosphäre, Deutsches Zentrum für Luft und Raumfahrt (DLR), Oberpfaffenhofen, Germany
}

${ }^{*}$ Correspondence to: J. S. Wagner, Institute of Meteorology and Geophysics, University of Innsbruck, Innrain 52, A-6020

Innsbruck, Austria. E-mail: johannes.s.wagner@gmail.com

The mesoscale structure of a mature polar low was studied on the basis of highresolution airborne measurements and numerical modelling. A polar low was measured by light detection and ranging (lidar) and dropsonde observations over the Norwegian Sea on 3 and 4 March 2008. Lidar observations provided crosssections of water-vapour mixing ratio, backscatter ratio and horizontal wind speed around the polar low and through its centre. Mesoscale structures, such as shallow convection in a cold-air outbreak, a dry intrusion in the eye-like centre of the cyclone and deep convection surrounding it could be identified. Numerical simulations were performed with the European Centre for Medium-Range Weather Forecasts (ECMWF) Integrated Forecast System (IFS) and a high-resolution, polar version of the Weather Research and Forecasting (WRF) model. WRF simulations reproduced these structures and showed that the polar low had a warm, upper-level core with descending motions. The eye-like centre had a diameter of about 100-150 km and was characterized by rather stable stratification, horizontally constant potential temperatures and calm winds. Beyond the centre, wind speeds increased rapidly. The observed radial wind and temperature profiles support previous idealized simulations. Several WRF sensitivity tests showed the influence of the initialization time and sensible and latent heat fluxes from the surface on the simulated polar-low development. The polar-low simulations were more accurate in runs starting at the mature stage. Heat fluxes from the surface were important for the polar-low energetics, especially at the final stages. Copyright (c) 2011 Royal Meteorological Society

Key Words: IPY-THORPEX; polar WRF model; polar low eye

Received 8 November 2010; Revised 6 April 2011; Accepted 4 May 2011; Published online in Wiley Online Library 19 July 2011

Citation: Wagner JS, Gohm A, Dörnbrack A, Schäfler A. 2011. The mesoscale structure of a polar low: airborne lidar measurements and simulations. Q. J. R. Meteorol. Soc. 137: 1516-1531. DOI:10.1002/qj.857

\section{Introduction}

Polar lows are subsynoptic-scale cyclones which occur in cold air masses poleward of the main baroclinic zone (Harold et al., 1999; Rasmussen and Turner, 2003). These maritime, short-lived storms with wind speeds near or above gale force are sometimes denoted as Arctic hurricanes (Emanuel and Rotunno, 1989) and have always been a great danger for coastal regions at high latitudes. For that reason especially, Arctic meteorologists have been interested in understanding the respective formation and development processes and in improving polar-low forecasts (Rasmussen and Turner, 2003). The examination of formation mechanisms and life cycles of polar mesocyclones is often a great challenge, as polar lows can appear and dissolve very quickly and surfacebased observations are rare in Arctic regions. In addition to the short lifetimes, the small horizontal scales $(200-1000 \mathrm{~km}$ in diameter) make it difficult for current operational numerical weather prediction models to simulate polar lows properly. To enhance the knowledge of these intense Arctic 


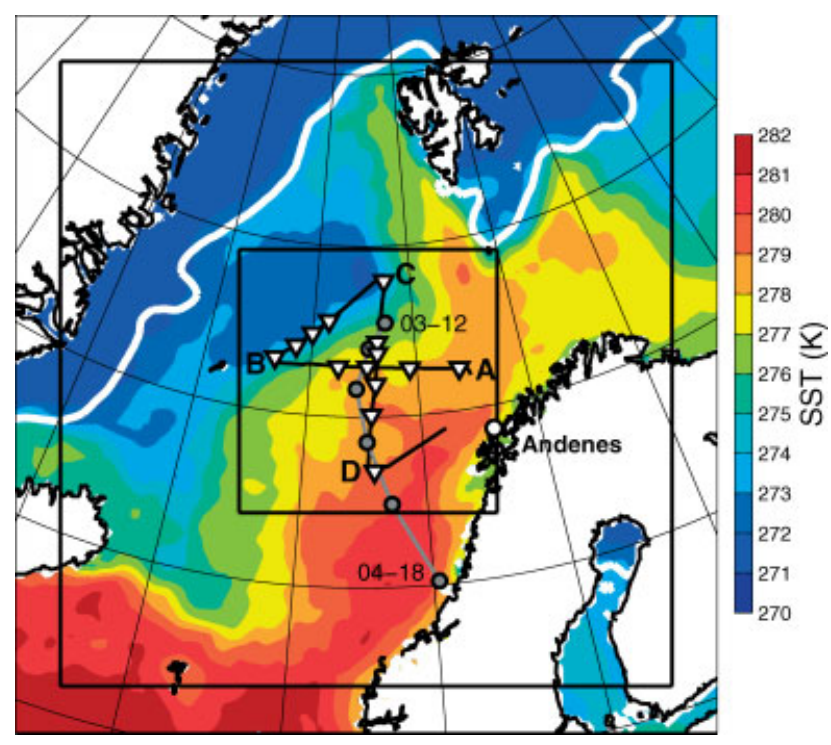

Figure 1. Observational area and domains for numerical modelling (black boxes with grid-point distances of 18 (not shown), 6 and $2 \mathrm{~km}$ ). OSTIA sea-surface temperatures $(\mathrm{K})$ are plotted as contour surfaces and the ice edge is shown as the $10 \%$ contour line of the OSTIA fractional sea ice (white line). The flight track is marked with A-B-C-D (the mission lasted from 1515 to 1800 UTC on 3 March 2008) and dropsonde locations are displayed as triangles. The path of the polar low deduced from the ECMWF analysis is illustrated with filled circles: the starting point is at 1200 UTC on 3 March 2008, time-steps are $6 \mathrm{~h}$ and the end point is at 1800 UTC on 4 March 2008. Andenes is labelled with a white circle.

weather phenomena, study their mesoscale structure and improve their predictability, several scientific investigations and field campaigns were conducted. Most of them were based on airborne in situ measurements (Harrold and Browning, 1969; Reed and Duncan, 1987; Shapiro et al., 1987; Renfrew et al., 2008; Brümmer et al., 2009), radar observations (Browning and Dicks, 2001) and satellite imagery (e.g. Blechschmidt, 2008; Claud et al., 2009).

Airborne lidar systems to study mesoscale structures of polar lows were deployed for the first time during the international field campaign International Polar Year-THe Observing System Research and Predictability EXperiment (IPY-THORPEX), ${ }^{*}$ which took place during the International Polar Year (IPY) from 28 February-17 March 2008. The observations over the Norwegian and Barents Seas focused mainly on the investigation of polar lows. Because of relatively high sea-surface temperatures related to a branch of the Gulf Stream and a well-developed ice edge east of Greenland and around Svalbard (see Figure 1), these regions are known to offer ideal conditions for the formation and development of polar lows (Bracegirdle and Gray, 2008).

The principle observational platform of IPY-THORPEX was the research aircraft Falcon of the Deutsches Zentrum für Luft- und Raumfahrt (DLR), based at Andenes, Norway. The aircraft was equipped with a downward-looking Doppler lidar and a four-wavelength DIfferential Absorption Lidar (DIAL). For the first time, these unique lidar systems allowed simultaneous observations of horizontal and vertical winds, water vapour and backscatter ratio along extended flight legs in the Arctic. These observations provided two-dimensional cross-sections with high vertical and horizontal resolutions.

*http://www.pa.op.dlr.de/ipy_thorpex/
Additionally, about 150 dropsondes were released during the 15 research flights.

During the IPY-THORPEX campaign, two polar-low events occurred on 3-4 March and 16-17 March 2008. The evolution of the first polar low was observed by three successive research flights. In this investigation we concentrate on observations of the second flight of the 3-4 March case (Figure 1), as it provided measurements directly through the centre of the polar low during the mature stage of its evolution.

The main objective of this paper is to characterize the mesoscale structure of this observed polar-low case by analysis of the unique remote-sensing equipment. Especially, we want to prove that airborne lidar observations are beneficial to provide detailed characteristics of mesoscale structures. The reader might wonder why airborne lidar observations are useful for polar-low research at all, as the laser beam cannot penetrate intense clouds. However, one should recall that polar lows are rather shallow weather systems in contrast e.g. to tropical cyclones. Nadir-pointing lidar observations from an aircraft operating between 8 and $10 \mathrm{~km}$ altitude, therefore, do not only measure the cloud-top heights very accurately. The observations above the clouds, e.g. in the centre of the mesocyclone, or in the surroundings of the polar low reveal fascinating structures that require a detailed explanation.

Our lidar observations reveal mesoscale and small-scale features of wind, water vapour and aerosol concentration in the polar low, such as low-level wind maxima, dry intrusions and sharp gradients in backscatter intensity. A careful investigation of the observations and a preliminary comparison with six-hourly operational analyses of the European Centre for Medium-Range Weather Forecasts (ECMWF) asked for a careful selection of the numerical model. Therefore, our numerical simulations were performed with the ECMWF Integrated Forecasting System (IFS) to provide one-hourly output of the synoptic-scale weather evolution. Additionally, the polar version of the Weather Research and Forecasting (WRF) model-version 3.1.1, the so-called Polar WRF (Bromwich and Hines, 2008; Bromwich et al., 2009) -was used as a state-of-the-art high-resolution numerical model to investigate and analyze the observed cloud, temperature and wind structures in and around the observed polar low.

To resolve mesoscale structures, we choose a horizontal mesh size of $2 \mathrm{~km}$ in the innermost domain. Previous studies used coarser resolution models for polar-low simulations with grid resolutions of 50 and $25 \mathrm{~km}$ (Gronas et al., 1987; Claud et al., 2004), $17 \mathrm{~km}$ (Browning and Dicks, 2001), $12 \mathrm{~km}$ (Bracegirdle and Gray, 2009), $10 \mathrm{~km}$ (Brümmer et al., 2009) and $5 \mathrm{~km}$ (Wu and Petty, 2010). Yanase et al. (2002) performed one of the first simulations of a polar low with a convection-permitting resolution of $2 \mathrm{~km}$.

In order to present reliable numerical simulations, we performed a systematic validation and several sensitivity tests. Furthermore, the impact of the initialization time of the WRF simulations and the contributions of sensible and latent-heat surface fluxes on the polar low development were investigated.

The airborne observations and numerical simulations are combined to study the mesoscale structure of this polarlow case. We demonstrate the outstanding possibility of identifying and analyzing mesoscale features like the coldair outbreak as well as the wind and temperature structure 
inside the polar low. This particular mission was the only flight for the 3-4 March polar-low case with multiple lidar observations in the centre of the polar low. Therefore, this study focuses on the investigation of the core structure. In the identification of the eye-like centre of the polar low especially, the lidar observations in concert with the highresolution numerical simulations were extremely beneficial. In contrast, the exclusive use of coarsely resolved dropsonde data leads to an offset of the location of the polar-low core compared with our method (cf. Føre et al., 2011). Additionally, our wind lidar data are compared with the results of Gray (1998), who studied the eye structures of polar and tropical cyclones by means of an idealized physical model (see the discussion about the eye structure in section 6). Our lidar data verify her results for polar cyclones.

This article is organized as follows. In section 2 the methods are described, while in section 3 a short overview of the synoptic situation and the development of the polar low is presented. In section 4 sensitivity tests are summarized. The mesoscale structures of the polar low are analyzed in section 5 and investigations of the polar-low centre are described in section 6. Concluding remarks are given in section 7.

\section{Methodology}

\subsection{Observations}

During IPY-THORPEX, a $2 \mu \mathrm{m}$ Doppler wind lidar and a four-wavelength DIAL were installed on board the Falcon aircraft, which generally flew at a constant altitude of about $8-10 \mathrm{~km}$ above sea level (ASL). The frequency shift of the emitted and received signals of the $2 \mu \mathrm{m}$ Doppler wind lidar is proportional to the line-of-sight wind velocity. By performing a conical scan beneath the aircraft, the horizontal wind vector can be calculated (Weissmann et al., 2005). The horizontal and vertical resolutions were about $6.7 \mathrm{~km}$ and $100 \mathrm{~m}$, respectively. Water vapour was observed by the nadir-pointing four-wavelength DIAL Water Vapour Lidar Experiment in Space (WALES: Wirth et al., 2009). The differential absorption of laser pulses at water-vapour absorbing and non-absorbing wavelengths gives information about the water-vapour content in the illuminated volume. The effective resolutions were $355 \mathrm{~m}$ vertically and $5.3 \mathrm{~km}$ horizontally. Additionally, the backscatter ratio at $1064 \mathrm{~nm}$ was used to identify aerosol and cloud layers.

Vertical profiles of the lidar observations were complemented by dropsondes providing information about the vertical structure of temperature, humidity, wind speed and wind direction. In addition, NOAA AVHRR IR channel 4 satellite images were used to follow the polar-low development in more detail (section 3 ).

The 3-4 March polar low was observed by three successive flight missions. The first one started during the developing stage at 1000 UTC and ended at 1330 UTC on 3 March. The second lasted from 1515 UTC to 1800 UTC on the same day, when the polar low reached its mature stage (see Figure 1). The last mission started at 1000 UTC and ended at about 1300 UTC on 4 March, at the final stage of the cyclone evolution.
Table I. Control and sensitivity runs.

\begin{tabular}{lll}
\hline Case & Physics & Start time \\
\hline CTRL & full physics & 0600 UTC 03 Mar \\
FPH-1202 & full physics & 1200 UTC 02 Mar \\
FPH-0003 & full physics & 0000 UTC 03 Mar \\
FPH-1203 & full physics & 1200 UTC 03 Mar \\
NOSFLX-1 & no surface fluxes & 0600 UTC 03 Mar \\
NOSFLX-2 & surface fluxes switched & 0600 UTC 03 Mar \\
& off at 0000 UTC 04 Mar & \\
\hline
\end{tabular}

\subsection{Numerical models}

Two numerical models, ECMWF IFS and WRF, were applied in this study. ECMWF operational analysis fields valid at $0000,0600,1200$ and 1800 UTC were supplemented by short-term forecasts, which were treated as 'pseudoanalyses'. To enhance the temporal resolution, a special forecast experiment with the operational set-up of March 2008 (T799 L91, cycle 32r2) was run four times a day, initialized by the operational analyses. It provided onehourly data up to $+5 \mathrm{~h}$ forecast time. These fields served as a reference for the predicted mesoscale cyclone tracks and intensity as well as for a comparison of simulated data with observations. The IPY-THORPEX dropsonde observations were assimilated by the four-dimensional variational analysis (4DVAR) system for producing both pseudo and operational analyses (C. Weihrauch, 2010, personal communication).

The mesoscale simulations were generated with the Polar WRF model, version 3.1.1. To adapt the WRF model to Arctic conditions, special modifications of the Polar Meteorology Group of the Byrd Polar Research Center at Ohio State University were implemented for polar regions. These modifications contain adaptions to the polar boundary layer, implementations of fractional sea ice, fractional snow cover and frozen soil physics in the NOAH land-surface model (Chen and Dudhia, 2001) and an improved heat transfer and surface energy balance for ice sheets (Bromwich and Hines, 2008; Bromwich et al., 2009).

As polar lows are maritime phenomena that depend strongly on the distribution of sea-surface temperature and sea ice, the new Operational Sea surface Temperature and sea Ice Analysis (OSTIA) data set (Stark et al., 2007) of the National Centre for Ocean Forecasting (NCOF) of the Met Office, United Kingdom, was employed for the first time in a polar-low simulation. This daily, global gridded dataset has a horizontal resolution of $0.05^{\circ}$ and brought considerable improvements in sea-surface temperature (SST) and seaice (SI) distributions compared with the National Centers for Environmental Prediction (NCEP) based dataset that was used to produce the ECMWF analysis at the time of the campaign. Note that the OSTIA SST and SI data were implemented in the ECMWF operational system on 30 September 2008. Fields of SST and SI were kept constant during the WRF simulations performed for this study.

The WRF model used three nested domains (two are shown in Figure 1) with horizontal grid-point distances of 18,6 and $2 \mathrm{~km}$, respectively, and 70 vertical-terrainfollowing $\eta$ levels. The two coarse grids used two-way nesting; the finest domain was computed by one-way nesting. The vertical mesh size was about $15 \mathrm{~m}$ near the 
surface, continuously increasing to $400 \mathrm{~m}$ at a height of $4000 \mathrm{~m}$, from which point it remained constant up to the model top at $50 \mathrm{hPa}$. A Rayleigh damping layer was set from $10 \mathrm{~km}$ to the upper lid of the model (Klemp et al., 2008).

Physical parametrizations of the control (CTRL) run used the Rapid Radiative Transfer Model (RRTM) longwave scheme (Mlawer et al., 1997), the Goddard shortwave scheme (Chou and Suarez, 1994) and the MellorYamada-Nakanishi-Niino (MYNN) 2.5 level prognostic turbulent kinetic energy (TKE) planetary boundary layer (PBL) scheme (Nakanishi and Niino, 2009). Microphysical processes were parametrized by the WSM6-class scheme (Hong and Lim, 2006; Dudhia et al., 2008), which contains water vapour, rain, snow, cloud ice, cloud water and graupel. We decided to use this parametrization as $\mathrm{Wu}$ and Petty (2010) compared bulk microphysics schemes in WRF simulations of polar lows and found that the WSM6 scheme produced cloud and precipitation processes most realistically. The Kain-Fritsch cumulus parametrization scheme (Kain and Fritsch, 1990, 1993; Kain, 2004) was used in the two outer domains, but was switched off for the innermost, convection-permitting grid. Initial and boundary conditions were provided by ECMWF operational analyses at model levels (91 vertical levels up to $0.1 \mathrm{hPa}$ ) with 6 hourly resolution. Test runs driven by the one-hourly ECMWF 'pseudo-analyses' did not improve the simulation results in the target area. WRF fields are available every two hours for the second $(6 \mathrm{~km})$ and every hour for the third (2 km) domain.

For comparison with observations and the depiction of model data along the flight track, the gridded model fields were spatially and temporally interpolated following the method of Schäfler et al. (2010). Note also that all model fields on horizontal sections presented in this study were temporally interpolated when they were compared, e.g. with satellite images.

\subsection{Data quality}

The data availability of both lidars is reduced by tropospheric clouds and curved flight segments. It amounts to $35.7 \%$ for water-vapour mixing ratio, $91.8 \%$ for backscatter ratio and $52.8 \%$ for horizontal wind speed for the second mission on 3 March 2008.

A comparison between the lidar observations and the 14 dropsondes that were released during the presented flight (see Figure 1) shows a relative difference for watervapour mixing ratio of $3.8 \%$ and confirms the reliability of both instruments to measure water vapour accurately. This is consistent with Harnisch et al. (2011), who show relative differences between dropsondes and DIAL WALES observations of $4.2 \%$ in the lower troposphere during a research campaign in the Tropics. Furthermore, a recent intercomparison study of different water-vapour lidars that were operated during the field experiment 'Convective and Orographically Induced Precipitation Study' (COPS) in 2007 revealed a low systematic error (bias of 2\%) for DIAL WALES (Bhawar et al., 2011). The comparison of the wind lidar data with the dropsonde horizontal wind velocities showed a relative difference of $3.5 \%$ for the second mission.

\section{Synoptic situation}

The studied polar low formed in a baroclinic convergence zone at the western edge of an already existing synoptic-scale low-pressure system with core pressure of less than $988 \mathrm{hPa}$. At 1000 UTC on 3 March 2008 the synoptic low was situated northwest of the Norwegian coast. The associated low-level flow at the western side caused an intense cold-air outbreak east of Greenland (Figure 2(a)). At this location, an intense trough was present (dashed line in Figure 2(a)). Some hours before, between 0000 and 0600 UTC on 3 March, this trough intensified and the baroclinic disturbance developed. Closed isobars of sea-level pressure in the centre of the polar low first occurred in the ECMWF analysis at about 1500 UTC (see also Figure 2(b), valid for 1601 UTC). Interestingly, the pressure in the polar-low core did not decrease significantly below the pressure of the synoptic low. The core pressure remained nearly constant at about $986 \mathrm{hPa}$ until 1800 UTC on 3 March. After this time, the pressure in the polar-low centre increased intensely up to $999 \mathrm{hPa}$ at 1800 UTC on 4 March, when the polar low made landfall at the Norwegian coast.

The NOAA AVHRR IR channel 4 satellite image and the ECMWF sea-level pressure analysis at 1001 UTC on 3 March (Figure 2(a)) show the synoptic low, the core of which consisted of two parts. From the western part northward towards the ice edge an intense trough (dashed line) with strong directional wind shear is visible. West of the trough, in the intense cold-air outbreak, polar air was advected southwards from ice-covered surfaces to the relatively warm, open ocean (see Figure 1). With warmer air to the east and colder air to the west, the thermal wind in the boundary layer was opposed to the steering-level wind in the cold-air outbreak. Consequently, in this reverse-shear flow situation wind speed decreased with height. Together with warmer air coming from the southeast, zones of strong lowlevel baroclinicity were generated south and southwest of Svalbard. Satellite imagery depicts these convergence lines as white (i.e. cold) areas, obviously representing regions with deep convection attaining maximum altitudes of about 6-7 km ASL. These lines were oriented in the south-north direction along $0^{\circ} \mathrm{E}$ and in the west-east direction along about $74^{\circ} \mathrm{N}$. At the intersection of the two frontal lines, cyclonic motion was initiated.

A polar low with a self-contained core evolved from the baroclinic disturbance in the afternoon as shown in Figure 2(b) at 1601 UTC. The satellite image shows the polar low at the time of the second research flight. The flight track is labelled by the letters A-B-C-D and the locations of dropsondes are marked with triangles. Around point B, i.e. in the region of the cold-air outbreak, shallow clouds and cloud streets indicate shallow convection in the polar air over the relatively warm ocean. Deep convection forms the comma-shaped cloud structure of the polar low with a cloud free eye-like zone around dropsonde D10. The core of the polar low was encircled by a well-developed eyewall in the north and a less pronounced eyewall in the south. Further south, another Arctic front is visible by the nearly zonally oriented cloud band, which marks the southern edge of the cold-air outbreak.

Complementary ECMWF analysis fields, valid at 1600 UTC on 3 March, illustrate the meteorological situation at the time of the research flight (Figures 3 and 4). 
(a)

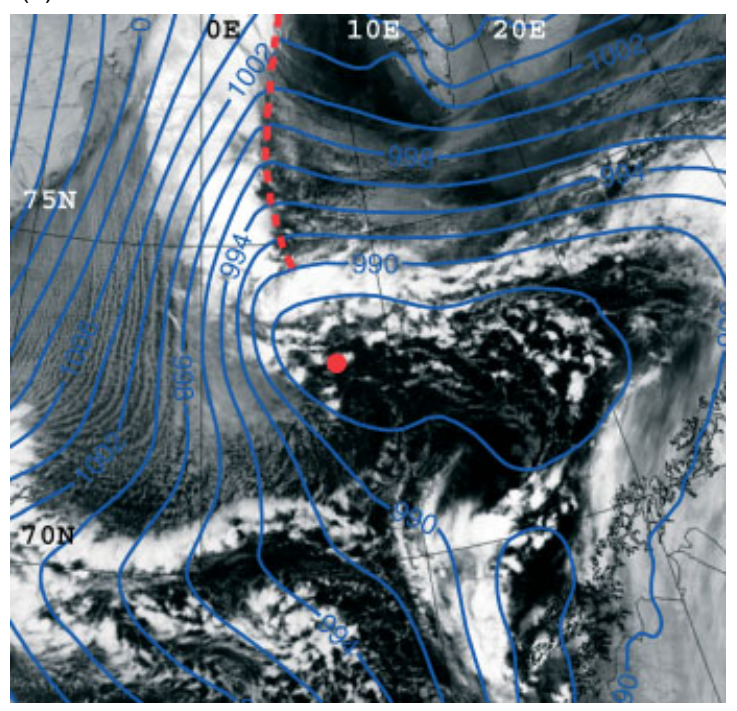

(c)

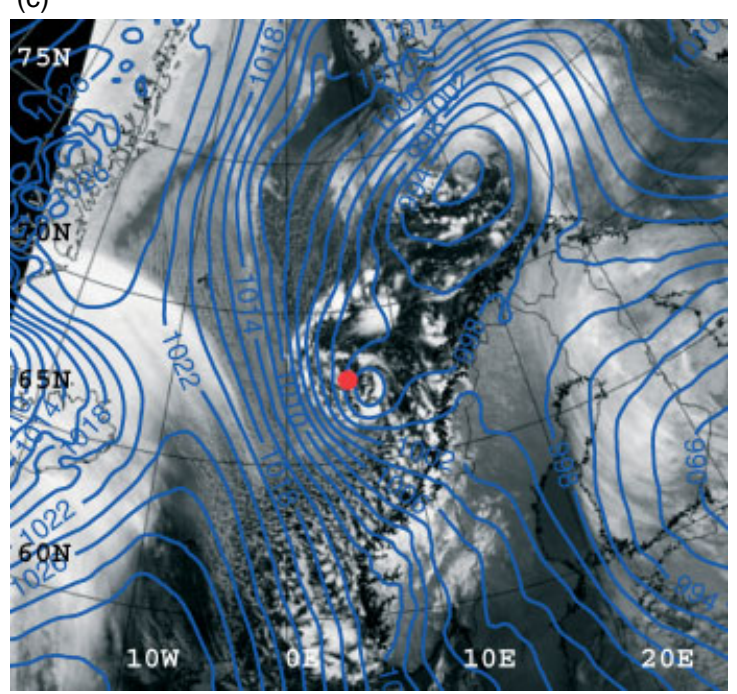

(b)

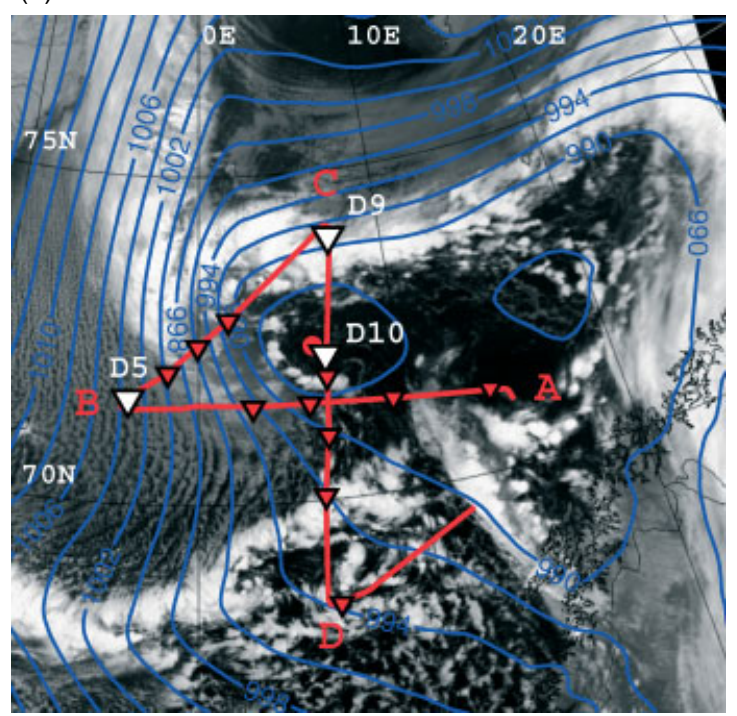

(d)

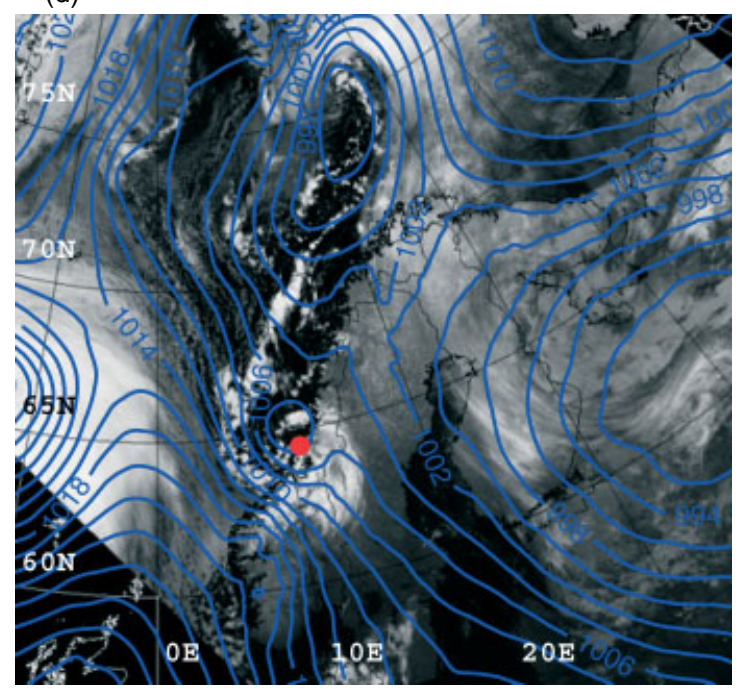

Figure 2. NOAA AVHRR IR channel 4 satellite images (grey shading) and ECMWF analysis of sea-level pressure (hPa) as contour lines with 2 hPa increments at (a) 1001 UTC on 3 March, (b) 1601 UTC on 3 March, (c) 1115 UTC on 4 March and (d) 1955 UTC on 4 March 2008. Dots mark the centre of the polar low in the satellite images. Note that (c) and (d) show the polar low in a larger sector. The surface trough in (a) is marked with a dashed line. The flight track (line A-B-C-D) and the locations of dropsondes (triangles) are shown in (b). Dropsondes D5, D9 and D10 are used in this article.

Strong horizontal gradients of equivalent potential temperature, intense wind shear and convergence occurred along the frontal lines at the $925 \mathrm{hPa}$ pressure surface (Figure 3). Warm air masses were advected around the polar low at its northeastern side and strengthened the low-level baroclinicity. Føre et al. (2011) showed that upper-level forcing only marginally influenced the polar-low evolution at the time of the observation. This is confirmed by Figure 4, which shows a weak upper-level positive potential vorticity anomaly located south (i.e. downstream) of the surface polar low.

During the next $20 \mathrm{~h}$, the cloud structure of the polar low altered from a comma-like to a spiral-like cloud system, as illustrated by the satellite image at 1115 UTC on 4 March (Figure 2(c)). The propagation speed of the polar low was rather low (about 5-10 $\mathrm{m} \mathrm{s}^{-1}$ ) until about 0600 UTC on the same day. Afterwards, the polar low accelerated up to $15-25 \mathrm{~m} \mathrm{~s}^{-1}$ and it moved southeastwards towards the Norwegian coast. The satellite image at 1955 UTC on 4 March (Figure 2(d)) captures the landfall of the polar low at the Norwegian coast. ECMWF wind speeds in the eyewall were between 25 and $30 \mathrm{~m} \mathrm{~s}^{-1}$ and the sea-level pressure in the centre had increased to about $999 \mathrm{hPa}$. The cyclone dissolved rapidly in the next few hours when it moved over the Continent.

\section{Simulation of the polar low}

The lidar observations (see section 5) provided crosssections with complex atmospheric structures as the aircraft flew through the different air masses and zones of the polar low. In order to investigate these structures and to identify their origin, mesoscale numerical simulations with the Polar WRF were performed. The verification of the simulations with lidar data revealed that a careful selection of the model set-up was necessary. Furthermore, the initialization time of the simulations was crucial for a proper agreement between observed and simulated mesoscale structures. To obtain the best model run, the simulations were initialized at different times. In addition to the control simulation (CTRL), three 


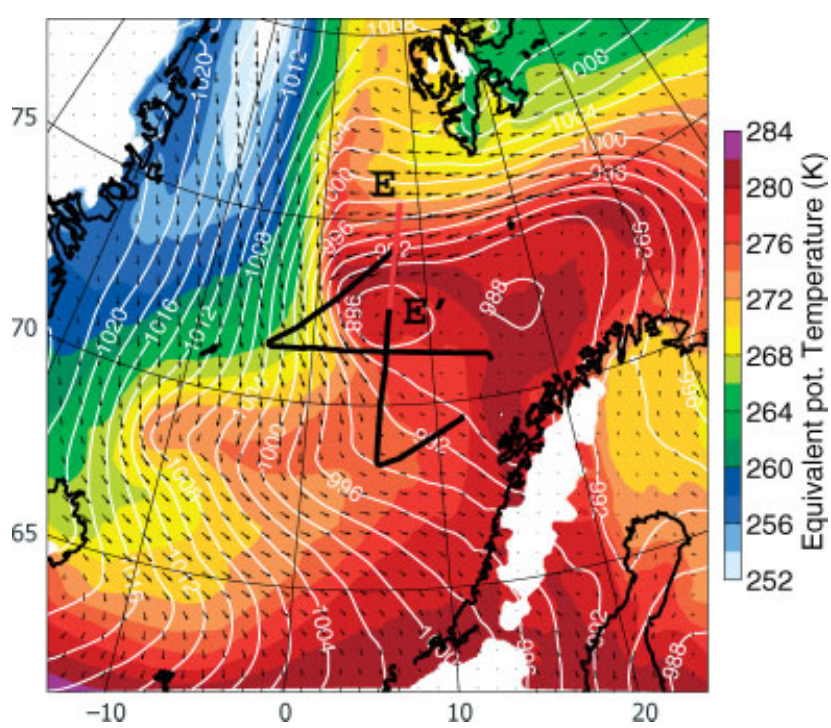

Figure 3. ECMWF analysis valid at 1600 UTC on 3 March 2008: equivalent potential temperature $(\mathrm{K})$ as shaded contours and wind vectors at $925 \mathrm{hPa}$, sea-level pressure $(\mathrm{hPa})$ as white contour lines with $2 \mathrm{hPa}$ increments. The cross-section along E-E' is used in section 6.

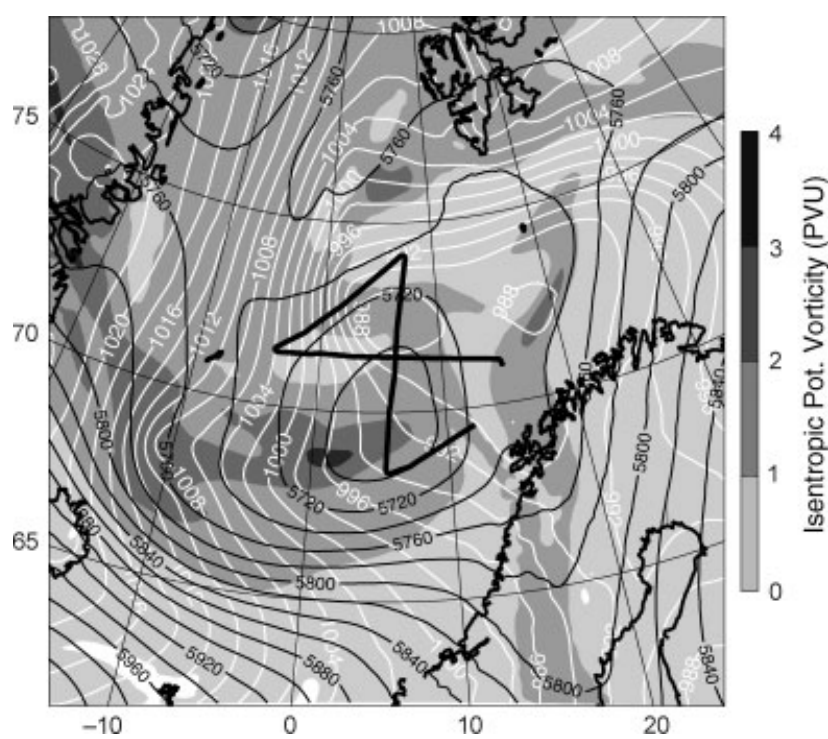

Figure 4. ECMWF analysis valid at 1600 UTC on 3 March 2008: Isentropic potential vorticity (PVU) at $\Theta=285 \mathrm{~K}$ as shaded contours, sea-leve pressure $(\mathrm{hPa})$ as white contour lines with $2 \mathrm{hPa}$ increments, geopotentia height $(\mathrm{gpm})$ of $450 \mathrm{hPa}$ surface as black contour lines with $20 \mathrm{gpm}$ increments.

runs with full physics were performed starting at 1200 UTC on 2 March (FPH-1202), 0000 UTC on 3 March (FPH-0003) and 1200 UTC on 3 March (FPH-1203), respectively (see Table I).

As surface heat fluxes (sensible and latent) reached values near $800 \mathrm{~W} \mathrm{~m}^{-2}$ between 0600 and 1800 UTC on 4 March in the WRF CTRL run, we supposed that these fluxes played an important role at least in the final stage of the polar low. To test this hypothesis, surface sensible and latent heat fluxes were switched off for the whole duration of the sensitivity run NOSFLX-1. In run NOSFLX-2, the fluxes were switched off after $18 \mathrm{~h}$ of integration at 0000 UTC on 4 March. As in the CTRL run, both runs were initialized at 0600 UTC on 3 March.

\subsection{Initialization time}

To analyze the impact of the initialization time on the numerical results, we compared the observed cloud structures with simulated satellite images at the time of the second research flight (Figure 5). As reference we used the infrared satellite image and ECMWF sea-level pressure analysis valid at 1737 UTC on 3 March 2008 as plotted in Figure 5(a). All other panels show simulated sea-level pressure and outgoing long-wave radiation at the top of the atmosphere for the different runs as listed in Table I.

The polar-low simulation FPH-1202 (longest time period to the mature stage) did not produce a core with closed isobars at this time (Figure 5(b)) and the simulated commalike clouds deviated strongly from the verifying satellite image (Figure 5(a)). Furthermore, the Arctic front south of the polar low was not simulated properly either. The simulated cloud structures were generally in good agreement with the satellite observation for the FPH-0003, CTRL and FPH-1203 runs, respectively. However, in contrast to the other simulations, the simulated shallow convection in the cold-air outbreak of the FPH-1203 run (Figure 5(e)) could not form elongated cloud streets, probably because of the short simulation time of only $5 \mathrm{~h}$ until 1737 UTC. This seems to be in agreement with convective roll cloud simulations of Liu et al. (2004, 2006), who analyzed the cloud structures after an integration time of $10 \mathrm{~h}$.

As can be seen from Figure 5(c), the eye-like structure seemed to be best simulated in the FPH-0003 run, but the centre of the polar low and its southern eyewall were positioned too far south. The location of the polar low was better simulated in the CTRL and FPH-1203 runs (Figure 5(d) and (e)).

Figure 6 shows the tracks and evolution of the minimum sea-level pressure of the polar-low centre for simulations with different initialization times. The tracks obtained from the ECMWF analysis and the IR satellite images served as verification. The centre of the modelled polar lows (WRF and ECMWF) was defined as the local minimum of sea-level pressure. As already mentioned, the pressure of the polar low did not fall below the pressure of the synoptic low. Core pressures before 1200 UTC on 3 March were related to the large-scale low-pressure system. For the satellite imagery, the location of the polar-low centre was deduced subjectively from the cloud structure (see the red bullets in Figure 2).

Altogether, Figure 6 reveals that the simulations fit the verifying analysis better the closer to the mature stage of the polar low they start. The tracks and core pressures in the CTRL and FPH-1203 runs match best with the analysis. Also, the track of the FPH-1202 run fitted the analysis and satellite paths. However, the simulated polar low did not form a proper core in this run (see also Figure 5(b)). This results in an incorrectly simulated development of the core pressure (Figure 6(b)), which was up to $3 \mathrm{hPa}$ too high throughout the simulation. Closed isobars in the centre could not be identified until 0600 UTC on 4 March in this FPH-1202 run. The core pressure development improved significantly when starting the simulation $12 \mathrm{~h}$ later (FPH-0003 run), although the polar low was shifted slightly eastwards between 0000 and 0600 UTC on 4 March. In summary, the initialization of the simulation at 0600 UTC on 3 March (CTRL run) showed the best agreement with observations and was used to investigate the mesoscale structures of the polar low in this study. 
(a)

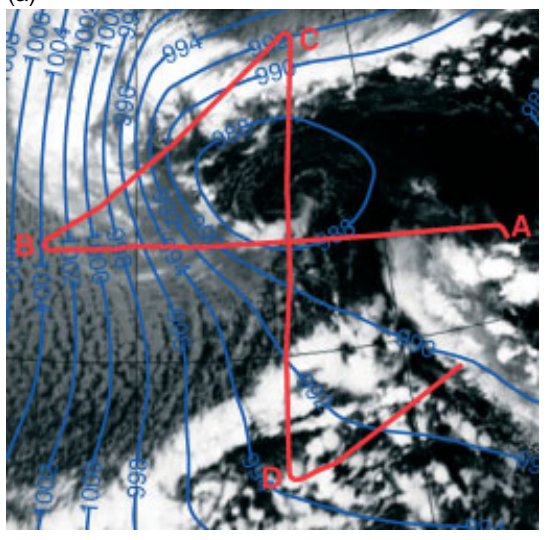

(d)

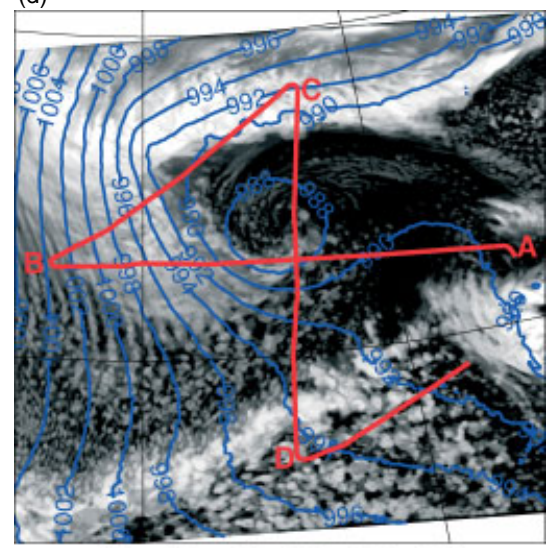

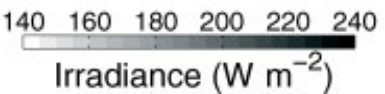

(b)
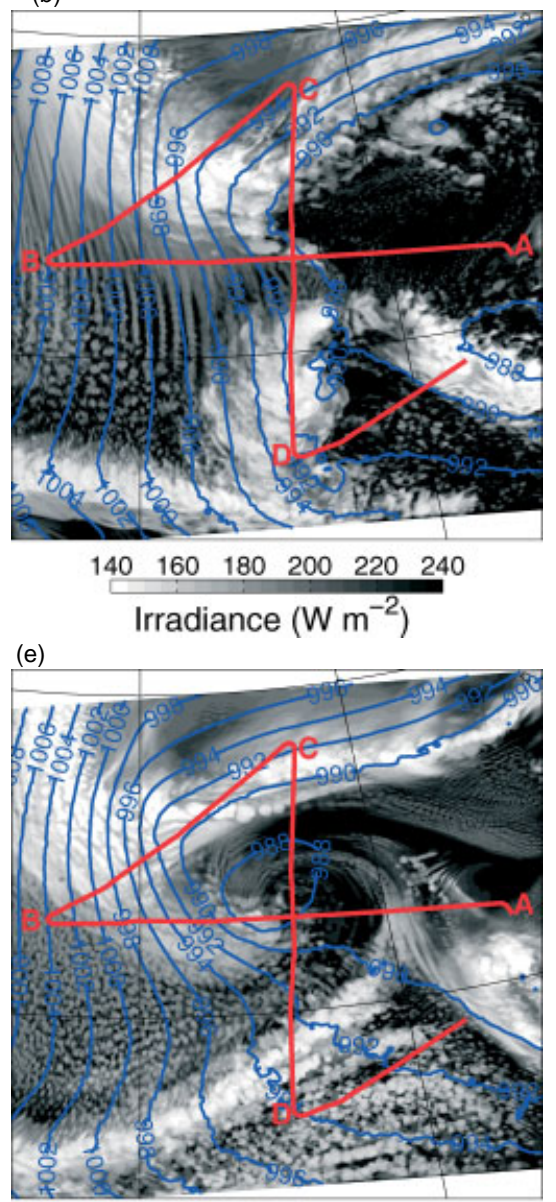

$\begin{array}{llllll}140 & 160 & 180 & 200 & 220 & 240\end{array}$

Irradiance $\left(\mathrm{W} \mathrm{m}^{-2}\right)$

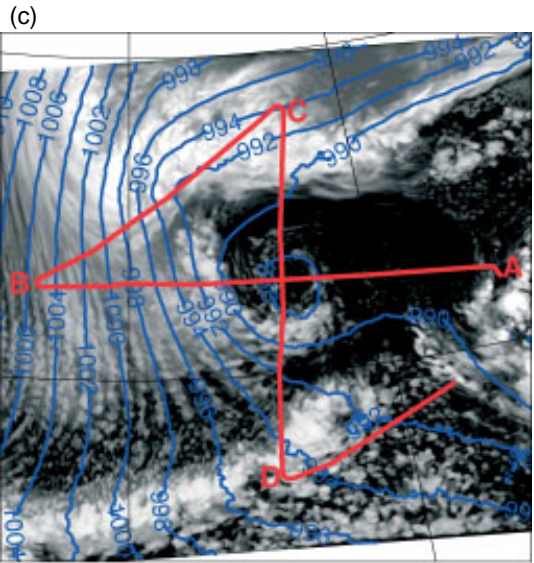

$$
\frac{140 \quad 160 \quad 180200 \quad 220 \quad 240}{\text { Irradiance }\left(\mathrm{W} \mathrm{m}^{-2}\right)}
$$

(f)

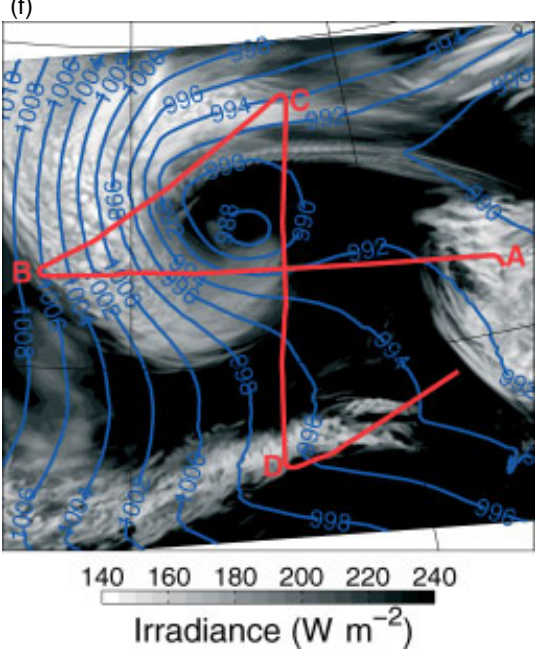

Figure 5. Polar low at 1737 UTC on 3 March 2008: (a) infrared satellite image as grey shaded contours and sea-level pressure (hPa) from ECMWF analysis as contour lines with $2 \mathrm{hPa}$ increments, WRF top-of-atmosphere outgoing long-wave radiation $\left(\mathrm{W} \mathrm{m}^{-2}\right)$ as grey shaded contours and sea-level pressure (hPa); (b) FPH-1202, (c) FPH-0003, (d) CTRL, (e) FPH-1203 and (f) NOSFLX-1.

\subsection{Sensitivity tests}

Figure 5(f) depicts the polar low as simulated by the NOSFLX-1 run. The missing energy flux from the surface prevented the formation of convection. In particular, shallow convection in the cold-air outbreak was not simulated at all. As less latent heat was released, temperatures were too cold (not shown) and the pressure in the polar-low core, which amongst other things can be used as a measure for cyclone intensity, was too high.

The polar-low track and core pressure evolution for the NOSFLX-1 and NOSFLX-2 runs are shown in Figure 7. When surface fluxes were switched off from the beginning (NOSFLX-1), a polar low was simulated and it followed the right track (Figure 7(a)). However, the pressure in the polarlow core had already increased too much by 1800 UTC on 3 March (Figure 7(b)). Furthermore, the $925 \mathrm{hPa}$ equivalent potential temperature near the centre of the polar low was simulated about $10 \mathrm{~K}$ colder than in the CTRL run at 1800 UTC on 4 March (not shown). The same behaviour was found when surface fluxes were switched off after 0000 UTC on 4 March (NOSFLX-2). In this case, the sea-level pressure was identical to the CTRL run until 0000 UTC on 4 March but increased strongly afterwards. Based on these results, we conclude that the surface fluxes were important for the energetics of the polar low, especially at its final stage. This finding is confirmed by Linders and Saetra (2010) and Føre et al. (2011), who estimated surface fluxes of the same polar low from dropsonde observations.

\section{Mesoscale structure of the polar low}

As mentioned above, one of the main advantages of the airborne lidar measurements during IPY-THORPEX was their ability to detect flow structures of the polar low underneath the aircraft with a spatial resolution only partially resolved by the discrete dropsonde observations. Figures 8 and 9 present vertical cross-sections of the airborne lidar measurements. Additionally, the corresponding numerical results of the WRF CTRL simulation spatially and temporally interpolated along the whole flight track are superimposed. The WRF CTRL run was initialized at 0600 UTC on 3 March 2008, about $10 \mathrm{~h}$ before the polar low developed its own core (between 1500 and 1600 UTC on 3 March 2008, see Figure 2(b)). The simulated polar low of this run matches the observed structures best, as demonstrated in the previous section 4. Before discussing the core region of the polar low, which was crossed midway during the southbound flight leg C-D (in Figures 8 and 9 centred at a distance of 
(a)
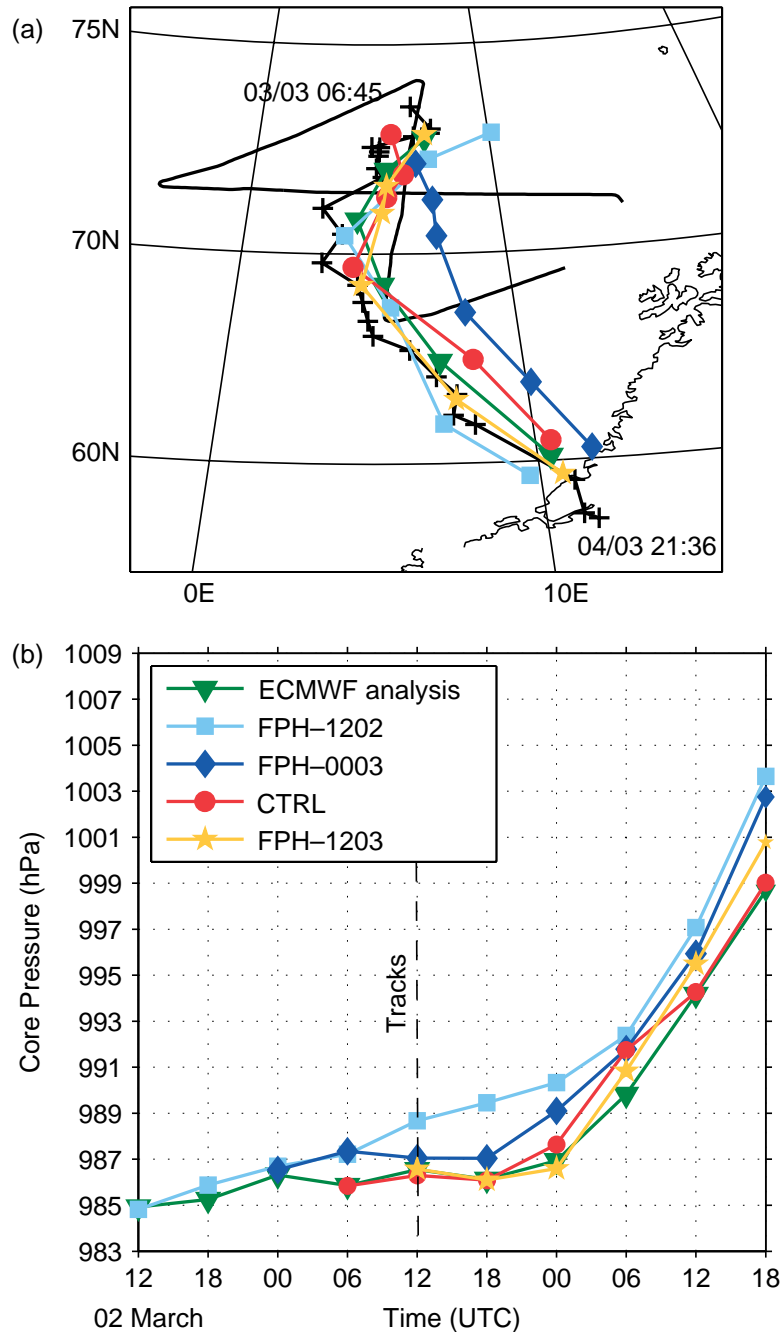

Figure 6. (a) Tracks of the polar low for different initialization times. (b) Evolution of sea-level pressure (hPa) in the core of the polar low. The start is at 1200 UTC on 3 March 2008 in (a) and 1200 UTC on 2 March 2008 in (b), time steps are $6 \mathrm{~h}$ and the end is at 1800 UTC on 4 March. The track obtained from satellite images is plotted with crosses and starts at 0645 UTC on 3 March and ends at 2136 UTC on 4 March 2008.

about $1330 \mathrm{~km}$ ), this section focuses on various atmospheric features observed by the lidars.

The diverse observed patterns in backscatter, water vapour and wind are assigned to the atmospheric features associated with the observed polar low. These are indicated and named at the bottom of Figures 8 and 9. The three most prominent features are the frontal zones, which the aircraft crossed several times, the shallow convection of the cold-air outbreak observed in the vicinity of waypoint B and the polar-low core crossed about midway on flight leg C-D.

The aerosol backscatter ratio reveals nearly 100\% cloudiness along the whole flight track. The deepest clouds were observed at the northernmost waypoint $\mathrm{C}$ of the research flight (Figure $8(\mathrm{c})$ ). These convective clouds with cloud-top heights of 6-7 km altitude are associated with the updraughts occurring at a nearly zonally oriented front north of the polar low. Due to the strong attenuation of the DIAL signal, no water vapour could be retrieved. In contrast, the wind lidar operating at $2 \mu \mathrm{m}$ partially penetrated the clouds and measured maximum velocities of about $20 \mathrm{~m} \mathrm{~s}^{-1}$ in the upper part of these clouds. WRF simulations (as shown in Figure 10) and especially the dropsonde D9 (Figure 11(b)) confirm the observed east, northeast wind directions of the (a)
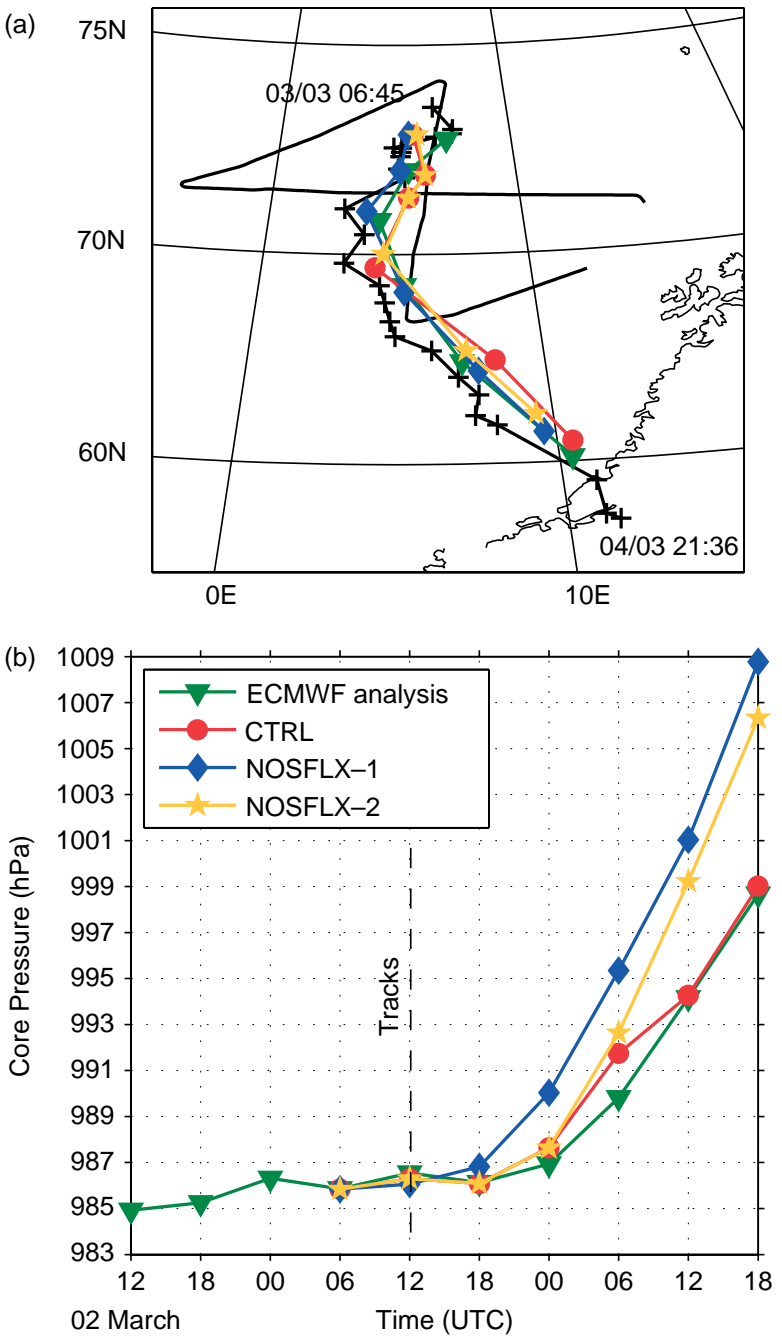

Figure 7. As in Figure 6 but for simulations without surface heat fluxes.

wind lidar. At the release position, however, the upper levels were less windy and the wind decreased nearly linearly with height in accordance with the lidar measurements and the WRF simulation.

The WRF results and the wind observations deviate slightly at almost all vertical levels at the position of dropsonde D9 (Figure 11(b)). The overestimated WRF winds can be explained by the northward shift of the simulated convective zone compared with the true position as found in the satellite image (see Figure 5(a) and (d)). Therefore, the simulated dropsonde profile D9 was displaced into the frontal zone, whereas the observations were taken north of it.

Deep convective clouds were also observed along the southeastern segments of the flight near waypoints A and D. These clouds belonged partly to the Arctic front south of the polar low as well as to convection in rather warm air masses. The Arctic front is best visible west of waypoint A (cf. the enhanced horizontal gradients in the simulated equivalent potential temperature in Figure 8(b)) by a band of vertically extended backscatter values at a distance of about $200 \mathrm{~km}$ (see Figure $8(\mathrm{c}))$. There, relatively high winds $\left(>10 \mathrm{~m} \mathrm{~s}^{-1}\right.$, Figure 9(a) and (b)) occurred. In contrast, the convective clouds in the warm air mass (sampled on the return flight from waypoint $\mathrm{D}$ to Andenes) are characterized by weak horizontal winds at all levels.

North of the Arctic front and on the rear side of the associated surface trough, a weak ridge showed distinctive 

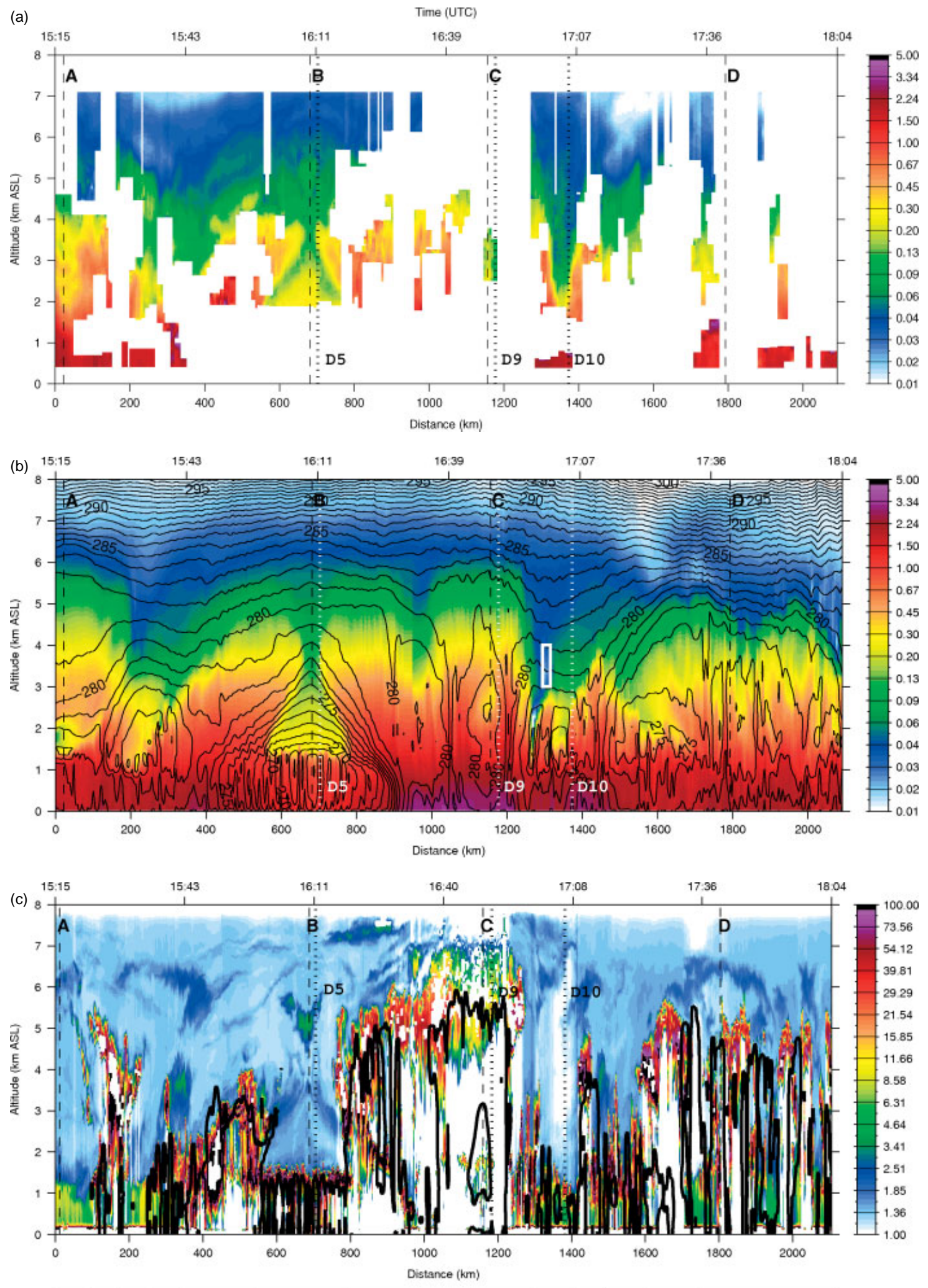

\begin{tabular}{|c|c|c|c|c|c|c|c|c|c|c|c|c|}
\hline 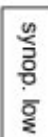 & 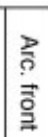 & 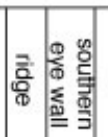 & 兽 & 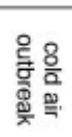 & $\begin{array}{l}1 \\
1 \\
1\end{array}$ & 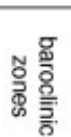 & 睎 & $\underset{\Phi}{\mathbb{\Phi}}$ & 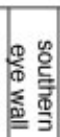 & 훙 & 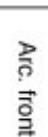 & 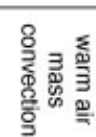 \\
\hline
\end{tabular}

Figure 8. Vertical cross-sections of the flight on 3 March 2008: water-vapour mixing ratio $\left(\mathrm{g} \mathrm{kg}^{-1}\right.$ ) of (a) lidar and (b) WRF CTRL as colour contours. (b) WRF CTRL equivalent potential temperature $(\mathrm{K})$ as black contour lines with interval $1 \mathrm{~K}$. (c) Lidar backscatter ratio as colour contours and $0.01 \mathrm{~g} \mathrm{~kg}^{-1}$ mixing ratio of WRF CTRL cloud hydrometeors as black contour line. All colour bars are on a logarithmic scale. Individual straight flight sections are marked with A-B-C-D (see flight track in Figure 1). Dotted vertical lines show locations of dropsondes (D5, D9, D10). Trajectories in Figure 12 were started in the white box plotted in (b). Below (c) the different regions of the flight track are described. 
(a)
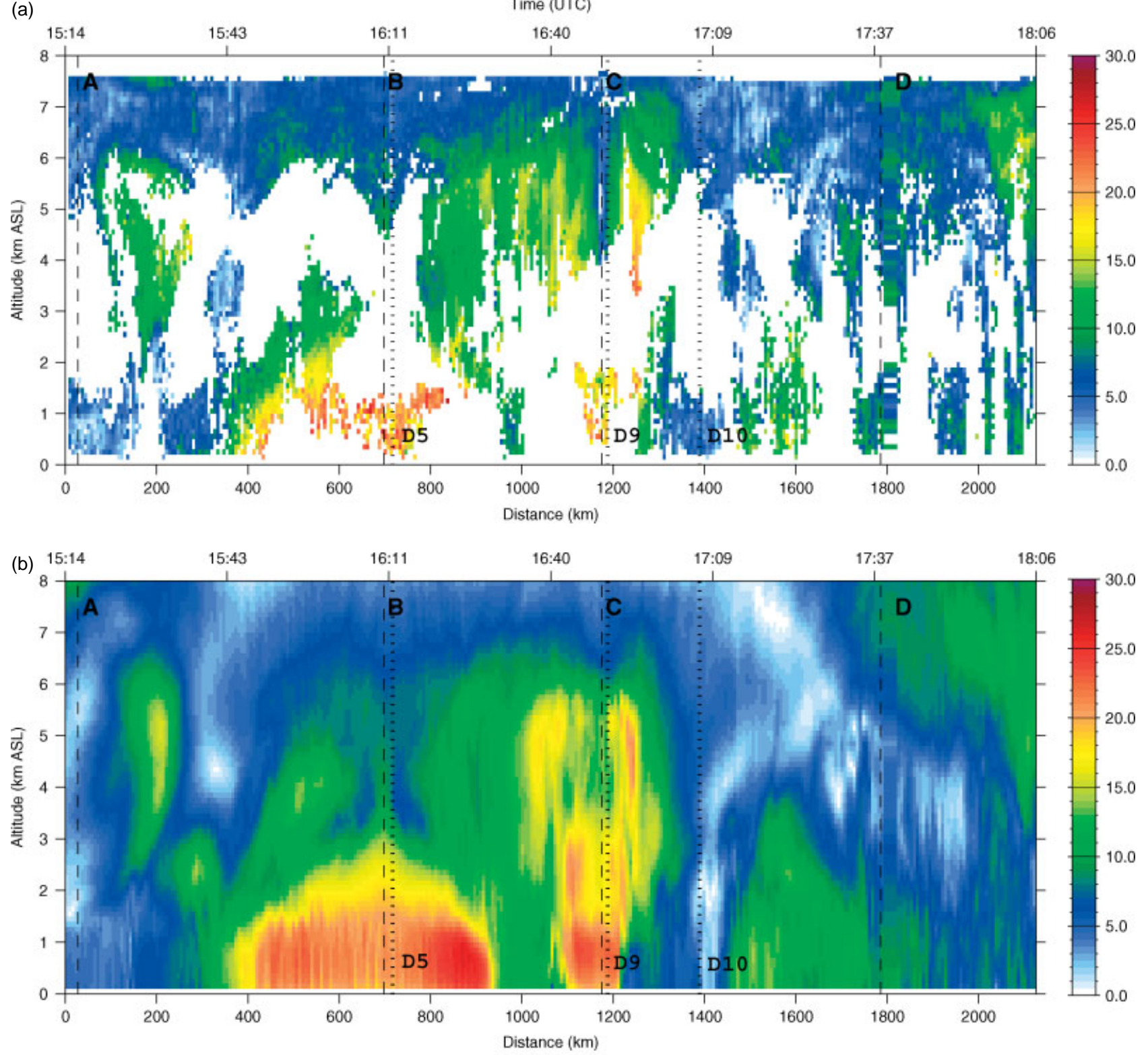

\begin{tabular}{|c|c|c|c|c|c|c|c|c|c|c|c|c|}
\hline 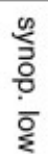 & 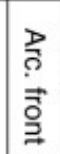 & 글: & : & 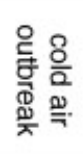 & $\begin{array}{l}1 \\
1 \\
1 \\
1\end{array}$ & 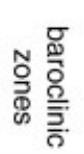 & 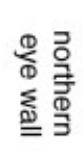 & $\underset{\mathbb{D}}{\stackrel{\mathbb{D}}{\mathbb{2}}}$ & 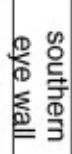 & চे চे & 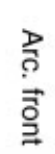 & 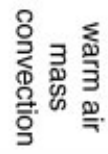 \\
\hline
\end{tabular}

Figure 9. As in Figure 8 but for horizontal wind speed $\left(\mathrm{m} \mathrm{s}^{-1}\right.$ ) (a) measured with the lidar and (b) simulated with the WRF CTRL model.

zones of dry air above $4-5 \mathrm{~km}$ ASL and low cloud cover underneath. Simulated vertical wind speeds indicate weak descending motions along this ridge in lower (Figure 10(a)) and upper levels (not shown). This ridge was more noticeable in the WRF simulation compared with the ECMWF analysis (compare Figure 3 with Figure 10(a)).

Interestingly, at the beginning of the straight westbound flight leg near waypoint $A$, the aircraft overflew a cloud-free zone of calm and warm air which was associated with the synoptic low-pressure system (Figure 2(b)). Measurements of water-vapour mixing and backscatter ratios indicate dry (water-vapour mixing ratio smaller than $1.0 \mathrm{~g} \mathrm{~kg}^{-1}$ ) and clear (backscatter ratio smaller than 3) air above $1.5 \mathrm{~km}$ ASL near point A (Figure 8(a) and (c)). Below this level a moist, well-mixed maritime boundary layer, probably enriched with sea-salt aerosols, was measured. As shown in Dörnbrack et al. (2010), sea spray is the main source of backscattering aerosols under the otherwise clean Arctic conditions over the sea.

Centred at around waypoint B (distance $550-800 \mathrm{~km}$ ) the convective clouds with tops between 5.5 and $7 \mathrm{~km}$ ASL were abruptly replaced by the low-level clouds associated with shallow convection. There, the intense cold air outbreak formed a sharp and horizontally nearly uniform cloud top marked by high backscatter ratios at about $1200 \mathrm{~m}$ ASL (between 550 and $800 \mathrm{~km}$ in Figure 8(c)). Above this altitude, the aerosol load of the Arctic air was very low and allowed the observation of two symmetrical bands of dry air (Figure 8(a)). WRF simulations revealed that entrainment of upper-level air at the turbulent edges of convective clouds generated these tilted dry intrusions. The symmetry of these observed and simulated patterns was caused as the aircraft 

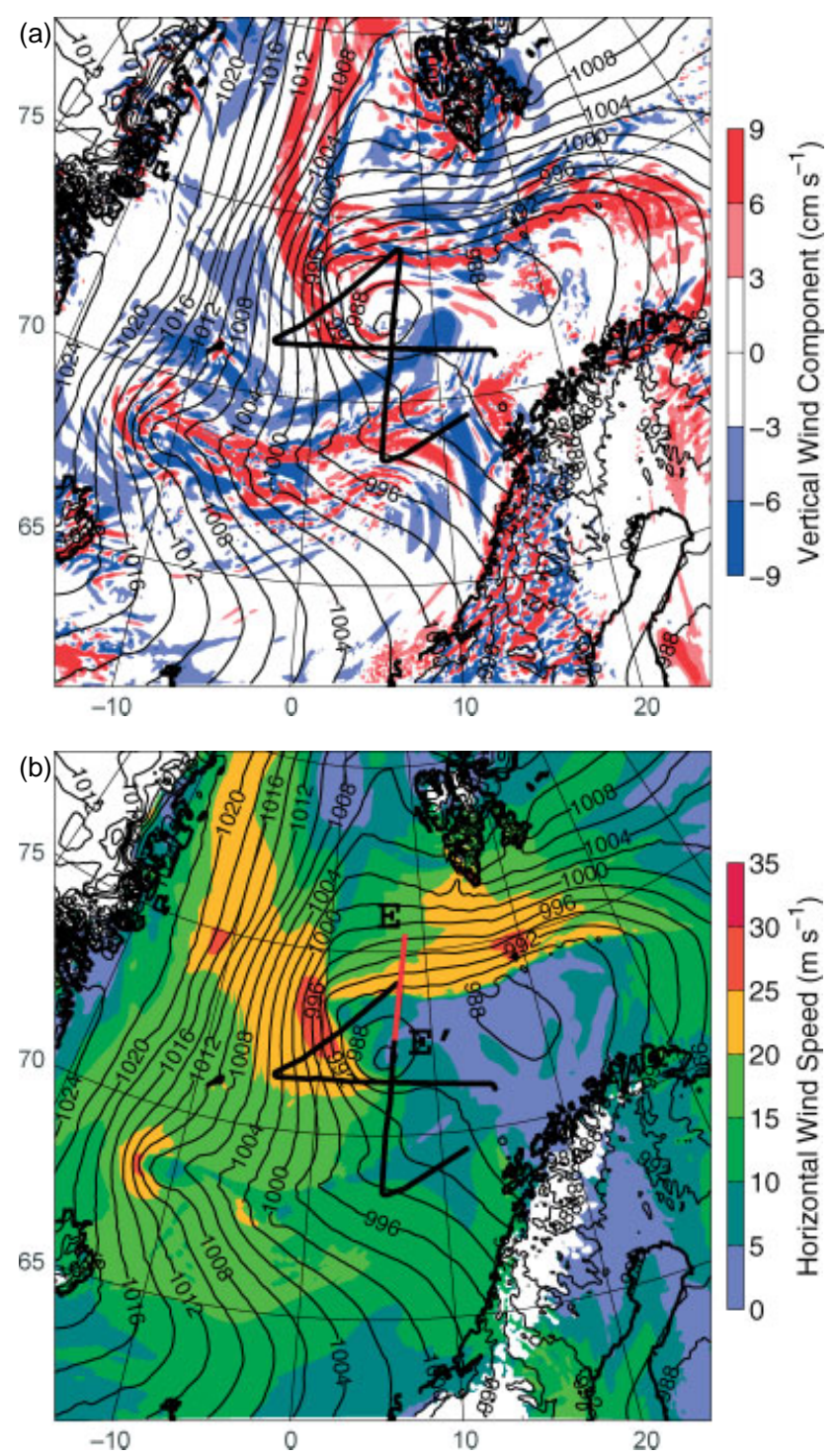

Figure 10. (a) WRF CTRL vertical wind speed $\left(\mathrm{cm} \mathrm{s}^{-1}\right)$ at $3 \mathrm{~km}$ ASL and (b) horizontal wind speed $\left(\mathrm{m} \mathrm{s}^{-1}\right)$ at $925 \mathrm{hPa}$ at 1600 UTC on 3 March 2008 as colour contours. Mean sea-level pressure (hPa) as black contour lines in (a) and (b) with $2 \mathrm{hPa}$ increments.

turned northeastwards at waypoint B and hence sampled the cold-air outbreak twice.

Another remarkable characteristics of the observations in the cold-air outbreak region is the high wind at lower levels. These large low-level winds and the decrease of wind speed with height in the reverse-shear flow are visible in the lidar measurements presented in Figure 9(a) and in the WRF CTRL simulations as shown in Figure 9(b). Although the horizontal resolution of the WRF simulation was rather coarse $(\Delta=2 \mathrm{~km})$, individual convective updraughts were simulated inside the maritime boundary layer. These cells are visible as vertical spikes in wind and water vapour (Figures 8(b) and 9(b)) and as separated regions of enhanced cloud hydrometeor mixing ratios (Figure $8(\mathrm{c})$ ).

The simulated sharp inversion layer and the low-level jet of the northerly reverse-shear flow were also measured by dropsonde D5 (Figure 11(a)). The vertical profiles of temperature, moisture and wind of this sonde were in closer agreement with the WRF model than with the ECMWF analysis. This profile also demonstrates the good match between dropsonde and lidar measurements, especially for water-vapour mixing ratio.

The region of the cold-air outbreak is enclosed by observations of the south-north oriented baroclinic zone which is visible in the (again symmetrical) extremely sharp horizontal gradients of equivalent potential temperature (Figures 3 and $8(\mathrm{~b})$ ). In this frontal zone, the lidar measured maximum wind speeds of about $28 \mathrm{~m} \mathrm{~s}^{-1}\left(26.5 \mathrm{~m} \mathrm{~s}^{-1}\right.$ simulated by the WRF model). Both lidar observations and WRF simulations showed that maximum wind speeds were found in a $1.2 \mathrm{~km}$ deep layer. The observations along the southbound flight leg from waypoint $\mathrm{C}$ show a sudden clearing and a reduction of wind speed at all altitudes (Figures 8(c) and 9(a)). This region is the core of the observed polar low, which will be discussed in the following section.

\section{The core region}

The core region of the polar low is characterized by an almost symmetric V-shaped intrusion of dry upper-level air with water-vapour mixing ratios lower than $0.2 \mathrm{~g} \mathrm{~kg}^{-1}$ (near $1400 \mathrm{~km}$ in Figure 8(a)). A similar (but more intense) intrusion was simulated by the WRF CTRL run (Figure 8(b)), however it was shifted slightly northward (at a distance of $1300 \mathrm{~km}$ ). The dry air at upper levels and the low wind speeds are verified by the measurements of dropsonde D10 (Figure 11(c)). The calm and dry core of the polar low had a diameter of approximately 100-150 km (Figures 8 and 9).

The high backscatter values below about $1500 \mathrm{~m}$ ASL confirm the existence of low-level clouds (Figure 8(c)). If the core region of a polar low is cloud-free then the centre is often called the eye of the mesocyclone, in association with its tropical counterpart (see Emanuel and Rotunno, 1989; Nordeng and Rasmussen, 1992). However, and as in our case, subsidence in polar regions is often too weak to produce a clear region, in contrast to tropical cyclones. Downward-bending contour lines of simulated equivalent potential temperature between 2.5 and $6 \mathrm{~km}$ ASL indicate a warm core of the polar low (see Figure 8(b)). The eye-like centre was surrounded by moister air masses north and south. There, the high backscatter values indicate convective clouds reaching higher levels in the north compared with the southern edge of the polar-low core (Figure 8(c)). These surrounding regions of intense convection could be associated with eyewalls. However, as seen in Figure 2(b) they do not form a closed ring as the updraughts of intense tropical cyclones do. Rather, the simulated watervapour mixing ratio shows a spiral band of dry air along a weak surface ridge on a horizontal section at $3.5 \mathrm{~km}$ ASL (Figure 12(a)). Descending motions dominate the numerical results in this band (cf. Figure 10(a)).

The origin of the dry air inside the polar low was traced back by calculating trajectories of air parcels released in a box with a horizontal size of $30 \times 30 \mathrm{~km}^{2}$ and a vertical depth of $1 \mathrm{~km}$. The release time of 1600 UTC on 3 March was selected when the polar low reached its mature stage. The centre of this box was placed inside the simulated eye-like structure, i.e. at a distance of $1300 \mathrm{~km}$ at $3.5 \mathrm{~km} \mathrm{ASL} \mathrm{(cf.}$ white box in Figure 8(b)). The driving wind field for the air parcels was taken from the WRF output. The backward trajectories yielded an average subsidence of about $500 \mathrm{~m}$ in $10 \mathrm{~h}$ (Figure 12(b)). This means that dry air was advected around the eastern side of the polar low and due to its weak 

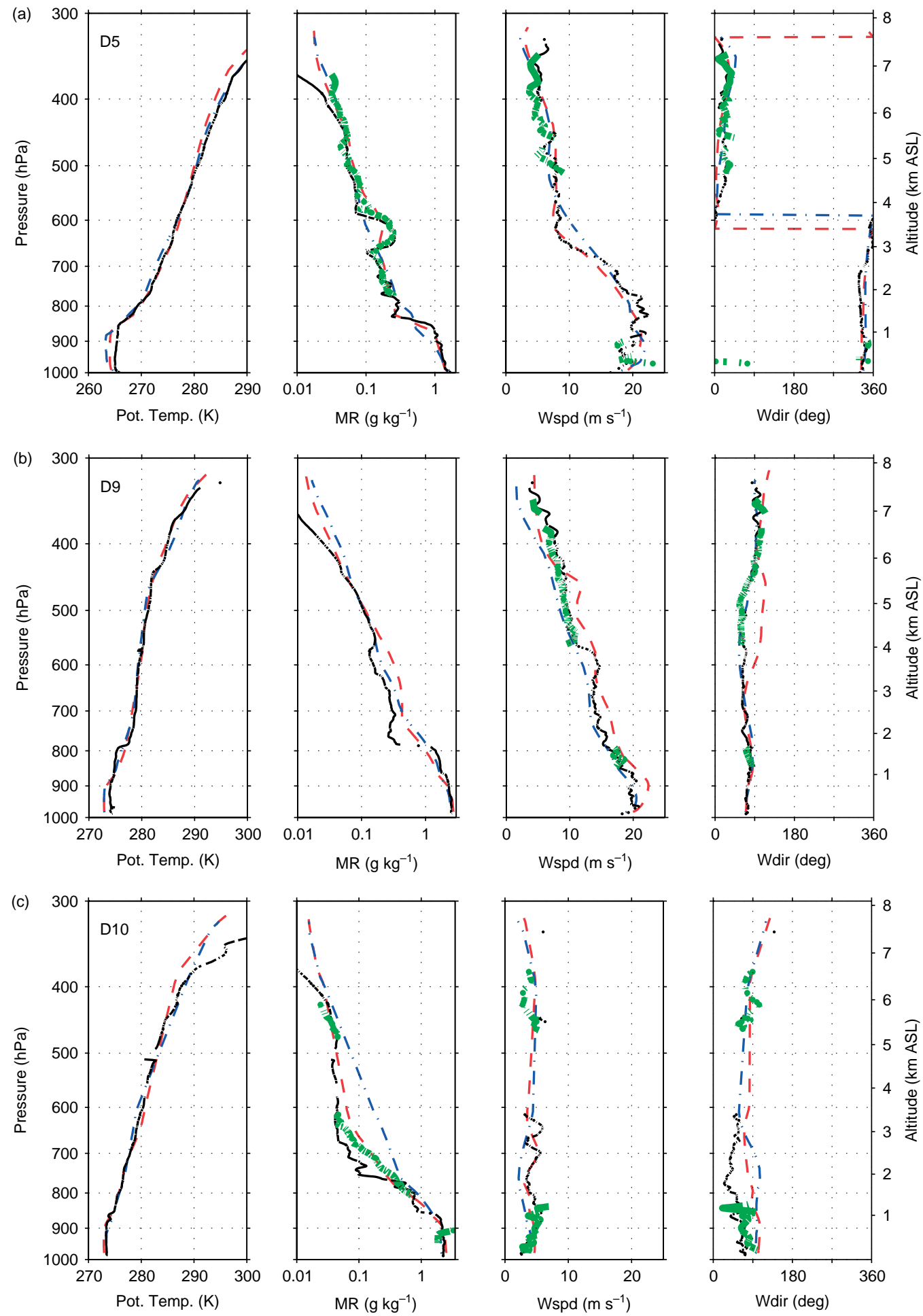

Figure 11. Profiles (a) D5 (1612 UTC on 3 March), (b) D9 (1651 UTC on 3 March) and (c) D10 (1707 UTC on 3 March): dropsonde (thin solid), lidar (thick solid), WRF CTRL (dashed), ECMWF (dash-dotted). From left to right: potential temperature (K), water-vapour mixing ratio ( $\mathrm{g} \mathrm{kg}^{-1}$ ), horizontal wind speed $\left(\mathrm{m} \mathrm{s}^{-1}\right)$ and wind direction (deg). See Figure 2(b) for the dropsonde location.

descent of about $1.4 \mathrm{~cm} \mathrm{~s}^{-1}$ it became even drier while approaching the core. Nordeng and Rasmussen (1992, their figure 16) showed numerical results indicating a reduced relative humidity of about $30-40 \%$ inside their simulated polar-low core. These values agree with our simulation results.

In the following, the wind lidar data and the WRF simulation results along the flight leg C-D will be directly contrasted with the idealized, axisymmetric primitiveequation model results by Gray (1998). Inside the core of the polar low, the wind lidar observed weak horizontal winds of about $5 \mathrm{~m} \mathrm{~s}^{-1}$ in the lowest $1000 \mathrm{~m}$ which increase radially outward (greater than $20 \mathrm{~m} \mathrm{~s}^{-1}$ in the north), cf. Figure 9(a). In Figure 13, all available wind lidar data between 0 and $1500 \mathrm{~m} \mathrm{ASL}$ are depicted for the core segment of the flight leg. In addition to the individual lidar observations, a layer-averaged wind was calculated for both the lidar data and the WRF CTRL simulation; see the solid and dashed lines in Figure 13. Note that the WRF boundary-layer winds were 

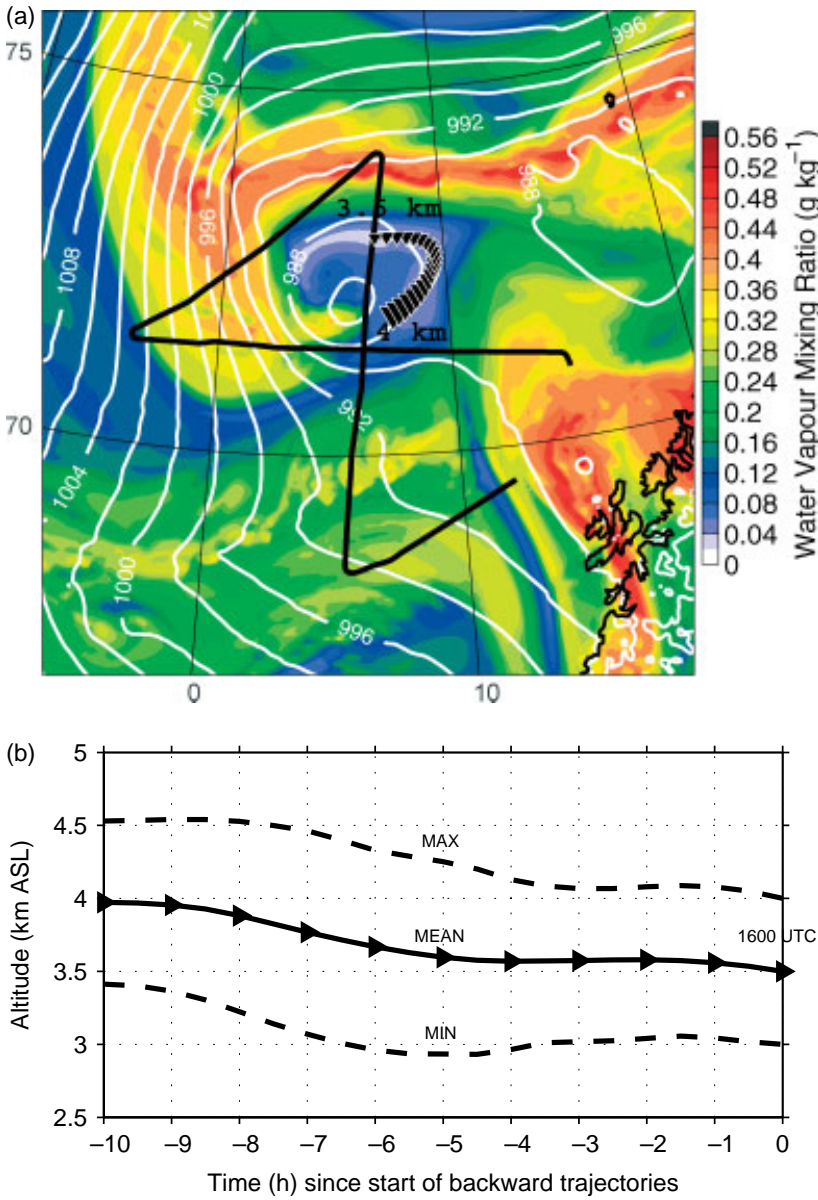

Figure 12. WRF CTRL backward-trajectories: (a) Water-vapour mixing ratio $\left(\mathrm{g} \mathrm{kg}^{-1}\right)$ as colour contours at $3.5 \mathrm{~km}$ ASL and sea-level pressure (hPa) as white contour lines with $2 \mathrm{hPa}$ increments at $1600 \mathrm{UTC}$ on $3 \mathrm{March}$ 2008. Black triangles show the averaged position of trajectories: the start was at 1600 UTC at $3.5 \mathrm{~km} \mathrm{ASL}$, the end was at 0600 UTC on 3 March 2008 at about $4 \mathrm{~km}$ ASL. (b) Mean, maximum and minimum altitudes of the trajectories versus time.

averaged over all available grid points. The mean boundarylayer winds reveal a sharp, almost step-like transition from the calm core to the high-wind cloudy regions surrounding it at the southern and northern edges.

In principle, the WRF model simulated the observed radial wind profile qualitatively and quantitatively with high accuracy. Only the displacement of the simulated convective zone (see also Figure 5(a) and (d)) in the northern eyewall results in a northward shift of the step-like increase of the WRF wind. The magnitude of the horizontal winds as measured by dropsondes D9 and D10 coincide with the wind lidar observations at the respective positions (see the bars covering the measured horizontal wind in Figure 13). However, due to their large spatial separation, they only provide a rough estimate of the true radial wind profiles as measured by the wind lidar. To facilitate a comparison with the azimuthal wind profiles as presented in figure 2 of Gray (1998), we assume that the observed and simulated horizontal wind is almost perpendicularly oriented along flight leg C-D.

The radial wind profiles of the lidar and WRF run agree qualitatively with the idealized simulations of Gray (1998, her figure 2). The nearly homogeneously distributed nonzero wind inside the observed polar-low core is probably caused by its north-south propagation, which is not

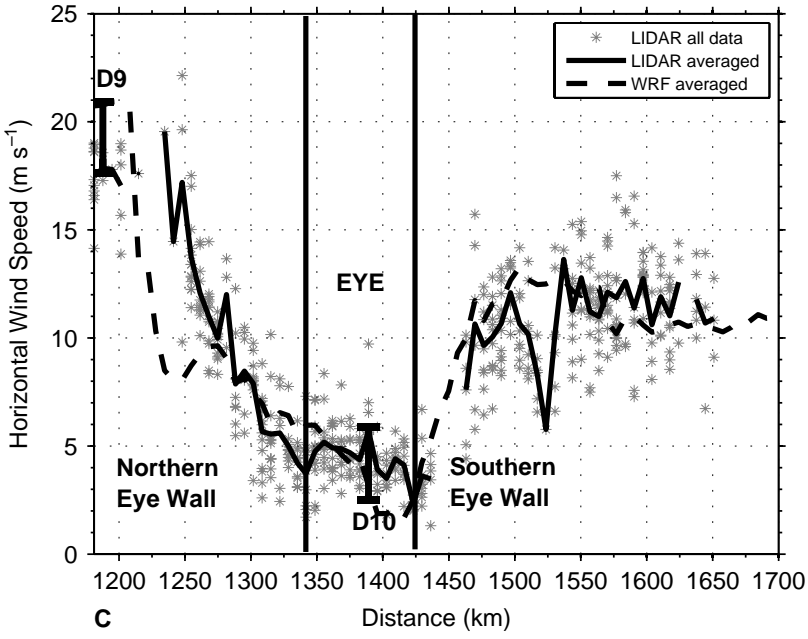

Figure 13. Horizontal wind speed $\left(\mathrm{m} \mathrm{s}^{-1}\right)$ between distance 1190 and $1700 \mathrm{~km}$ of the flight track (leg C-D) in the boundary layer $(0-1.5 \mathrm{~km}$ ASL). Dots show available lidar data at every grid point in this layer. Lines mark vertically averaged wind speeds of lidar (solid) and WRF CTRL (dashed) data. The range of wind speeds from dropsonde D9 and D10 is marked with vertical bars.

considered by the axisymmetric model of Gray (1998). Otherwise, the observed sharp increase by $15-20 \mathrm{~m} \mathrm{~s}^{-1}$ at the edges of the core matches her results perfectly. Surprisingly, the observed radius of about $50-60 \mathrm{~km}$ also has the same order of magnitude as the one in the idealized simulation of Gray (1998). In this sense, our wind lidar data are the first observations confirming her numerical results. The most significant difference between the idealized simulations by Gray (1998) and the airborne observations presented herein is the asymmetry of the observed polar low. The idealized simulations naturally produced axisymmetric cyclones, whereas baroclinicity and upper-level forcing generated a non-axisymmetric polar low over the Norwegian Sea.

To obtain both radial wind and temperature distributions that extend northward, WRF potential temperature and wind were vertically averaged along line E-E' (see Figures 3 and $10(\mathrm{~b}))$. Point E' is located in the centre of the observed polar low, while point $\mathrm{E}$ is located north of waypoint C. Figure 14 shows the respective profiles (thick solid lines) and the simulation results of Gray (1998) after $90 \mathrm{~h}$ integration time (thin solid lines). Altogether, the simulated radial wind and temperature profiles agree qualitatively with the results of Gray (1998).

The thermal structure of the idealized polar-low eye shows horizontal constant potential temperature (Figure 14(a)). The simulated neutral to weakly stable stratification (Gray, 1998) prevented the core from warming more than the surroundings. In contrast to Gray (1998), the observed polar low exhibited a stably stratified atmosphere in the centre (see dropsonde profile D10 in Figure 11(c)). As the air descended into the core of the observed polar low, the average potential temperature in the centre should be larger than in the surrounding region. However, inspection of Figure 14(a) reveals the opposite. In the vertical mean, the outer region was slightly warmer than the polar-low centre. A reason for this disagreement could again be the observed asymmetry of the polar low: the northward advection of warm air around its eastern side caused the marginally higher temperatures at the northern edge of the polar low core (see Figure 3 ). 

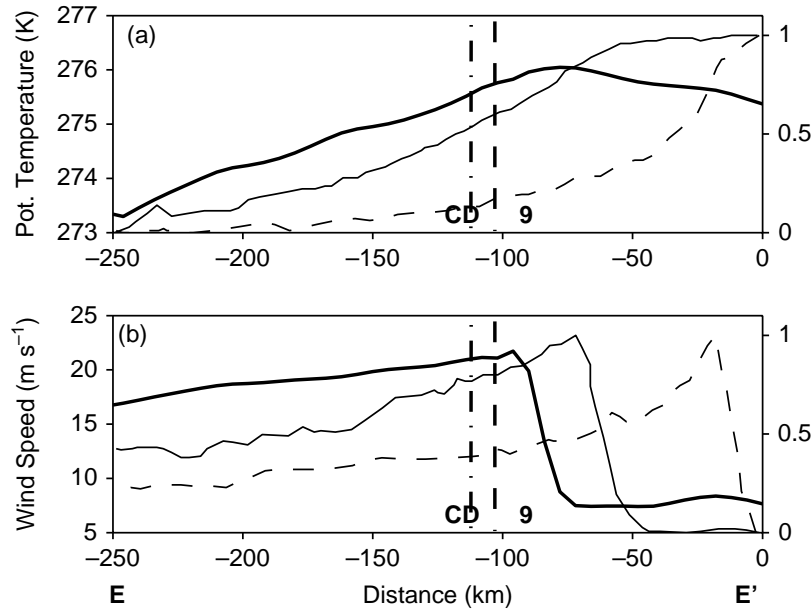

Figure 14. Radial distribution of (a) potential temperature and (b) horizontal wind speed. The thick solid lines mark the WRF CTRL distribution along line E-E' (see Figures 3 and Figure 10(b)) and belongs to the ordinate on the left side. Potential temperature $(\mathrm{K})$ was averaged vertically between 0 and $6 \mathrm{~km} \mathrm{ASL}$, wind speed $\left(\mathrm{m} \mathrm{s}^{-1}\right)$ between 0 and $1.5 \mathrm{~km}$ ASL. The locations of dropsonde D9 and waypoint C of the flight track are marked. The centre of the polar low is located on the abscissa at $x=0$. Thin solid (dashed) lines belong to the ordinate on the right side and show normalized results of the idealized polar-low (tropical cyclone) simulations of Gray (1998, her figures 2 and 4). The scaling was performed relative to the respective maximum values. Potential temperatures are about 1.2 times and wind speeds about 1.6 times greater for the tropical cyclone compared with the idealized polar low. Potential temperature was averaged vertically from $2-8 \mathrm{~km}$ ASL $(2.5-16.25 \mathrm{~km} \mathrm{ASL})$ in the polar low (tropical cyclone) case.

In summary, our wind lidar observations and the WRF simulation confirm the basic radial structure of the midlevel wind and potential temperature distributions of a polar low as discussed by Gray (1998). They also verify the fundamental difference of the azimuthal wind and temperature radial profiles of tropical cyclones (see thindashed lines in Figure 14).

\section{Conclusions}

Mesoscale structures of a mature polar low that developed over the Norwegian Sea on 3 March 2008 were studied. The investigations were primarily based on high-resolution airborne remote-sensing data of water vapour and wind beneath the aircraft, dropsonde data and satellite observations. Complementary, short-term forecasts were performed with the ECMWF IFS to produce 'pseudoanalyses' with one-hourly data output at a horizontal resolution of about $16 \mathrm{~km}$. Mesoscale numerical simulations with the advanced polar version of the WRF model were conducted at a horizontal resolution of $2 \mathrm{~km}$. The observational and numerical investigations focused on a selected research flight of the DLR Falcon that provided vertical cross-sections around and through the centre of this polar low during its mature stage.

In order to prove the reliability and the high accuracy of the mesoscale simulations, the sensitivity of the results to different model set-ups was tested in a comprehensive series of WRF runs. For example, the initialization time of the numerical simulations was varied. Simulations starting before 0000 UTC on 3 March 2008 produced an evolving polar low, however comparisons with lidar observations and ECMWF analyses were poor. Therefore, a control run starting at 0600 UTC on 3 March 2008 was selected as the reference simulation. At this time, a baroclinic disturbance already existed in the ECMWF analysis. The importance of the initialization time for the forecast of the same polar low was also demonstrated by Irvine et al. (2011) and McInnes et al. (2011). However, and in contrast to our study, the simulation results of McInnes et al. (2011) degraded the closer they started their model to the mature stage of the polar low.

The deactivation of sensible and latent heat fluxes from the surface did not affect the track of the polar low significantly. However, the absence of the surface forcing resulted in a considerable weakening of the polar low, especially at the final stage of its life cycle: the pressure in the polar-low core was simulated to be up to $10 \mathrm{hPa}$ too high and the equivalent potential temperature at $925 \mathrm{hPa}$ was about $10 \mathrm{~K}$ too low. These results demonstrate that the surface fluxes served as the main energy source for the maintenance of the polar low at its advanced stage. This result is in accordance with investigations of Føre et al. (2011) and Linders and Saetra (2010), who analyzed dropsonde observations of the same research flight. Linders and Saetra (2010) also concluded that energy fluxes from the ocean were equivalent to the CAPE values derived from dropsondes.

One remarkable feature of the lidar observations was the cold-air outbreak region at the western edge of the polar low. This region was characterized by a shallow convective boundary layer with a sharp inversion at about $1.5 \mathrm{~km} \mathrm{ASL}$ and strong northerly winds. Both the wind lidar observations and the numerical simulations demonstrated the existence of a reverse-shear flow in which wind speed decreased with height. Towards the polar low, the frontal and convergence zones revealed deep convection with maximum wind speeds up to $30 \mathrm{~m} \mathrm{~s}^{-1}$.

Our paper focuses especially on the investigation of the eye-like structure of the polar low. The southbound flight leg of the research flight crossed the polar-low centre precisely. This opened the opportunity to study the wind and temperature structure in the core and the surrounding convective clouds in detail. In particular, we compared the radial profiles of vertically averaged wind and temperature with the equivalent output of previous idealized polar-low simulations by Gray (1998). It has to be mentioned that lidar data of water-vapour mixing ratio, backscatter ratio and wind speed clearly indicated that the polar-low centre was crossed along flight leg $\mathrm{C}-\mathrm{D}$ of the second mission on 3 March 2008. This is in contrast to Linders and Saetra (2010) and Føre et al. (2011), who used cross-sections based on dropsonde observations and defined the polar-low centre along flight leg $\mathrm{B}-\mathrm{C}$ of the same flight. This indicates the advantage of high-resolution lidar data for the detection of mesoscale structures.

The nearly cloud-free centre of the polar low could be identified by calm winds, an upper-level warm core and dry descending air intruding into the centre. In our study, backward trajectories and simulated vertical wind velocities revealed that this intrusion was formed by descending dry air from upper levels. These descending air masses were advected around the eastern side of the polar low in about 10 h. Føre et al. (2011) demonstrated through PV inversion that the dry intrusion in the centre was produced by an upper-level PV anomaly. Dropsonde observations in the centre showed rather stable stratification, in contrast to idealized simulations by Gray (1998) that revealed neutral layering in the polar-low core. However, as there was warm 
air advection from the southeast, the air in the northern convective cells was slightly warmer than the core itself.

The vertically averaged boundary-layer winds showed a sharp transition from calm conditions inside the polar-low core to high velocities in the surroundings. The diameter of the polar-low core was about $100-150 \mathrm{~km}$, which is the same order of magnitude as the eyes of the idealized polar cyclones attaining a radius of $60 \mathrm{~km}$ (Gray, 1998).

Concluding, the study demonstrates that airborne lidar measurements offer great potential to investigate mesoscale weather phenomena such as polar lows that form in regions of sparse observations. The large number of vertical lidar profiles enables us to measure fine-scale atmospheric structures, which cannot be resolved by dropsonde observations. Further research flights through more axisymmetric polar lows deploying the combination of in situ and remote-sensing instrumentation could be very helpful to obtain more detailed information about polar-low eye structures. It would also be interesting to use airborne lidar techniques for different polar-low types and for the investigation of polar-low dynamics.

\section{Acknowledgements}

The authors are grateful to the pilots as well as the dropsonde and lidar operators who contributed to the successful realization of the IPY-THORPEX mission. We also thank Stephan Rahm, Christoph Kiemle, Martin Wirth and Reinhold Busen for the processing of the lidar and dropsonde data. We appreciate the Polar Meteorology Group of the Ohio State University and in particular Keith M. Hines and David H. Bromwich for providing the polar modifications of the WRF model. The meteorological data is kindly provided by the ECMWF in the framework of the special project 'Influence of non-hydrostatic gravity waves on the stratospheric flow field above Scandinavia'. This work was supported by the Austrian Ministry of Science BMWF as part of the UniInfrastrukturprogramm of the Forschungsplattform Scientific Computing at LFU Innsbruck. Johannes Wagner was supported by the scholarship 'Studienförderpreis 2010 des Deutschen Freundeskreises der Universitäten in Innsbruck e.V'. The international IPY-THORPEX campaign was partly funded by the Research Council of Norway through the project IPY-THORPEX Contract 175992/S30.

\section{References}

Bhawar R, Di Girolamo P, Summa D, Flamant C, Althausen D, Behrendt A, Kiemle C, Bosser P, Cacciani M, Champollion C, Di Iorio T, Engelmann R, Herold C, Müller D, Pal S, Wirth M, Wulfmeyer V. 2011. The water vapour intercomparison effort in the framework of the Convective and Orographically-induced Precipitation Study: airborne-to-ground-based and airborne-toairborne lidar systems. Q. J. R. Meteorol. Soc. 137(S1): 325-348. DOI:10.1002/qj.697.

Blechschmidt AM. 2008. A 2-year climatology of polar - low events over the Nordic Seas from satellite remote sensing. Geophys. Res. Lett. 35: L09815, DOI: 10.1029/2008GL033 706.

Bracegirdle TJ, Gray SL. 2008. An objective climatology of the dynamical forcing of polar lows in the Nordic seas. Int. J. Climatol. 28: 1903-1919.

Bracegirdle TJ, Gray SL. 2009. The dynamics of a polar low assessed using potential vorticity inversion. Q. J. R. Meteorol. Soc. 135: 880-893.

Bromwich DH, Hines KM. 2008. Development and testing of Polar Weather Research and Forecasting (WRF) model. Part I: Greenland ice sheet meteorology. Mon. Weather Rev. 136: 1971-1989.
Bromwich DH, Hines KM, Bai LS. 2009. Development and testing of Polar Weather Research and Forecasting model: 2. Arctic Ocean. J. Geophys. Res. 114: 1-22.

Browning KA, Dicks EM. 2001. Mesoscale structure of a polar low with strong upper-level forcing. Q. J. R. Meteorol. Soc. 127: 359-375.

Brümmer B, Müller G, Noer G. 2009. A polar low pair over the Norwegian Sea. Mon. Weather Rev. 137: 2559-2575.

Chen F, Dudhia J. 2001. Coupling an advanced land surface-hydrology model with the Penn State-NCAR MM5 modeling system. Part I: Model implementation and sensitivity. Mon. Weather Rev. 129: 569-585.

Chou MD, Suarez MJ. 1994. An efficient thermal infrared radiation parameterization for use in general circulation models, NASA Tech. Memo. 104606. NASA/Goddard Space Flight Center: Greenbelt, MD; $85 \mathrm{pp}$.

Claud C, Heinemann G, Raustein E, Mcmurdie L. 2004. Polar low le Cygne: Satellite observations and numerical simulations. Q. J. R. Meteorol. Soc. 130: 1075-1102.

Claud C, Funatsu BM, Noer G, Chaboureau JP. 2009. Observation of polar lows by the Advanced Microwave Sounding Unit: potential and limitations. Tellus 61A: 264-277.

Dörnbrack A, Stachlewska IS, Ritter C, Neuber R. 2010. Aerosol distribution around Svalbard during intense easterly winds. Atmos. Chem. Phys. 10: 1473-1490.

Dudhia J, Hong SY, Lim KS. 2008. A new method for representing mixedphase particle fall speeds in bulk microphysics parameterizations. J. Meteorol. Soc. Jpn 86A: 33-44.

Emanuel KA, Rotunno R. 1989. Polar lows as Arctic hurricanes. Tellus 41A: $1-17$.

Føre I, Kristjánsson JE, Saetra $\varnothing$, Breivik $\varnothing$, Røsting B, Shapiro M. 2011. The full life cycle of a polar low over the Norwegian Sea probed by three research aircraft flights. Q. J. R. Meteorol. Soc. DOI: 10.1002/qj.825.

Gray SL. 1998. Analysis of the eyes formed in simulated tropical cyclones and polar lows. Q. J. R. Meteorol. Soc. 124: 2357-2375.

Gronas S, Foss A, Lystad M. 1987. Numerical simulations of polar lows in the Norwegian Sea. Tellus 39A: 334-353.

Harnisch F, Weissmann M, Cardinali C, Wirth M. 2011. Experimental assimilation of DIAL water vapour observations in the ECMWF global model. Q. J. R. Meteorol. Soc. DOI:10.1002/qj.851.

Harold JM, Bigg GR, Turner J. 1999. Mesocyclone activity over the north-east Atlantic. Part 1: Vortex distribution and variability. Int. J. Climatol. 19: 1187-1204

Harrold TW, Browning KA. 1969. The polar low as a baroclinic disturbance. Q. J. R. Meteorol. Soc. 95: 710-723.

Hong SY, Lim JOJ. 2006. The WRF single-moment 6-class microphysics scheme (WSM6). J. Korean Meteorol. Soc. 42: 129-151.

Irvine EA, Gray SL, Methven J. 2011. Targeted observations of a polar low in the Norwegian Sea. Q. J. R. Meteorol. Soc. (in press).

Kain JS. 2004. The Kain-Fritsch convective parameterization: An update. J. Appl. Meteorol. 43: 170-181.

Kain JS, Fritsch JM. 1990. A one-dimensional entraining/detraining plume model and its application in convective parameterization. J. Atmos. Sci. 47: 2784-2802.

Kain JS, Fritsch JM. 1993. Convective parameterization for mesoscale models: The Kain-Fritsch scheme. In The representation of cumulus convection in numerical models, Meteor. Monogr. American Meteorological Society: Boston, MA; 46: 165-170.

Klemp JB, Dudhia J, Hassiotis AD. 2008. An upper gravity-waveabsorbing layer for NWP applications. Mon. Weather Rev. 136: 3987-4004.

Linders T, Saetra Ø. 2010. Can CAPE maintain polar lows? J. Atmos. Sci. 67: 2559-2571.

Liu AQ, Moore GWK, Tsuboki K, Renfrew IA. 2004. A high-resolution simulation of convective roll clouds during a cold-air outbreak. Geophys. Res. Lett. 31: L03101, DOI: 10.1029/2003GL018 530.

Liu AQ, Moore GWK, Tsuboki K, Renfrew IA. 2006. The effect of the sea-ice zone on the development of boundary-layer roll clouds during cold-air outbreaks. Boundary-Layer Meteorol. 118: 557-581.

McInnes H, Kristiansen J, Kristjánsson JE, Schyberg H. 2011. The role of horizontal resolution for polar - low simulations. Q. J. R. Meteorol. Soc. DOI: $10.1002 / q j .849$.

Mlawer EJ, Taubman SJ, Brown PD, Iacono MJ, Clough SA. 1997. Radiative transfer for inhomogeneous atmospheres: RRTM, a validated correlated- $k$ model for the long-wave. J. Geophys. Res. 102: $16663-16682$ 
Nakanishi M, Niino H. 2009. Development of an improved turbulence closure model for the atmospheric boundary layer. J. Meteorol. Soc. Jpn 87: 895-912.

Nordeng TE, Rasmussen EA. 1992. A most beautiful polar low. A case study of a polar - low development in the Bear Island region. Tellus 44A: 81-99.

Rasmussen EA, Turner J. 2003. Polar lows: Mesoscale weather systems in the polar regions. Cambridge University Press: Cambridge, UK.

Reed RJ, Duncan CN. 1987. Baroclinic instability as a mechanism for the serial development of polar lows: a case study. Tellus 39A: 376-384.

Renfrew IA, Petersen GN, Outten S, Sproson D, Moore GWK, Hay C, Ohigashi T, Zhang S, Kristjánsson JE, Føre I, Ólafsson H, Gray SL, Irvine EA, Bovis K, Brown PRA, Swinbank R, Haine T, Lawrence A Pickart RS, Shapiro M, Woolley A. 2008. The Greenland flow distortion experiment. Bull. Am. Meteorol. Soc. 89: 1307-1324.

Schäfler A, Dörnbrack A, Kiemle C, Rahm S, Wirth M. 2010. Tropospheric water vapour transport as determined from airborne lidar measurements. J. Atmos. Oceanic Technol. 27: 2017-2030.
Shapiro MA, Fedor LS, Hampel T. 1987. Research aircraft measurements of a polar low over the Norwegian Sea. Tellus 39A: 272-306.

Stark JD, Donlon CJ, Martin MJ, McCulloch ME. 2007. OSTIA: An operational, high-resolution, real time, global sea-surface temperature analysis system. In OCEANS 2007 - Europe. DOI: 10.1109/OCEANSE.2007.4302 251. IEEE: Piscataway, NJ.

Weissmann M, Busen R, Dörnbrack A, Rahm S, Reitebuch O. 2005. Targeted observations with an airborne wind lidar. J. Atmos. Oceanic Technol. 22: 1706-1719.

Wirth M, Fix A, Mahnke P, Schwarzer H, Schrandt F, Ehret G. 2009. The airborne multi-wavelength water vapor differential absorption lidar WALES: system design and performance. Appl. Phys. B 96: $201-213$.

Wu L, Petty GW. 2010. Intercomparison of bulk microphysics schemes in model simulations of polar lows. Mon. Weather Rev. 138: 2211-2228

Yanase W, Niino H, Saito K. 2002. High-resolution numerical simulation of a polar low. Geophys. Res. Lett. 29: 1658-1661. 